\title{
¿Por qué hay tanta inseguridad económica en América Latina?
}

\section{Dani Rodrik \\ Universidad de Harvard dani-rodrik@harvard.edu}

La idea de que una inseguridad económica generalizada amenaza el respaldo político a las reformas en curso orientadas al mercado ha pasado a ser una de las más escuchadas en los debates actuales sobre los asuntos latinoamericanos. Por lo tanto, ocuparse de tal inseguridad parece ser un componente clave de la agenda inconclusa de las reformas latinoamericanas. El autor sostiene que en América Latina la inseguridad económica es multifacética y proviene de muchas fuentes que se nutren recíprocamente. Parte de la inseguridad se debe a la declinación de la protección del empleo y la mayor volatilidad de los resultados de los hogares, parte a flujos de capital erráticos y la inestabilidad sistémica generada por el divorcio entre los instrumentos de estabilización y la economía real y, por último, parte importante a la debilidad de las instituciones de expresión (voz) y de representación. Los programas de protección social per se sólo dan una ayuda parcial. Habrá que complementarlos con políticas macroeconómicas, en particular las relativas a los flujos de capital y el tipo de cambio, que contribuyan más a la estabilidad de la economía real, y con la relajación del control que ejercen los mercados financieros sobre los instrumentos de la política macroeconómica. Asimismo, tendrán que tener acceso a instituciones representativas — sindicatos, partidos políticos y órganos legislativos - con mayor sensibilidad y legitimidad que las que existen actualmente. Pero tal vez lo que más necesita América Latina es una visión de cómo se puede mantener la cohesión social frente a grandes desigualdades y resultados volátiles, agravados ambos por una confianza creciente en las fuerzas del mercado. La región tendrá que desarrollar una visión que ayude a aliviar la tensión entre las fuerzas del mercado y las ansias de seguridad económica. 


\title{
I
}

\section{Introducción}

Durante los años noventa el ingreso per cápita en América Latina y el Caribe creció a una tasa media anual de un $2 \%$, tras haber caído a una tasa de casi $1 \%$ durante los años ochenta. El desempeño en los noventa se mantuvo a la zaga del ritmo de expansión económica al que la región estaba acostumbrada antes de la crisis de la deuda de 1982; pero da esperanzas de que podría estarse dejando atrás definitivamente la "década perdida" de los ochenta. No obstante, la región sigue siendo presa de un nivel desconcertante de inseguridad económica. La idea de que la inseguridad económica generalizada pone en peligro el respaldo político que se presta a las reformas en curso orientadas al mercado ha pasado a ser una de las cantilenas más comunes en los debates actuales sobre los asuntos latinoamericanos.
El problema se hace evidente en las últimas encuestas realizadas en la región. Una gran encuesta transnacional de 14 países latinoamericanos concluyó recientemente que $61 \%$ de los encuestados pensaba que sus padres habían vivido mejor que ellos. Además, menos de la mitad de los encuestados (46\%) pensaba que sus hijos terminarían viviendo mejor que ellos, porcentaje que variaba desde $30 \%$ en México hasta $61 \%$ en Chile (cuadro 1).

La misma encuesta detectó una fuerte demanda de seguro social en la región. Casi tres cuartos de los encuestados favorecían un mayor gasto en seguro de desempleo y más de $80 \%$ expresaban el deseo de que se gastara más en pensiones. Además, estas demandas incluían a todos los grupos sociales. La preferencia por un mayor gasto en pensiones y seguro de desempleo

CUADRO 1

\begin{abstract}
América Latina (14 países): Respuestas a una encuesta sobre cambios previstos en los niveles de vida, 1999

(En porcentaje, a menos que se indique otra cosa)
\end{abstract}

\begin{tabular}{|c|c|c|c|c|c|c|c|c|c|c|c|c|c|c|c|}
\hline \multicolumn{8}{|c|}{ Muestra total } & \multicolumn{8}{|l|}{ Países } \\
\hline $\mathrm{N}^{\mathrm{o}}$ & $\%$ & $\begin{array}{l}\text { Argen- } \\
\text { tina }\end{array}$ & $\begin{array}{c}\text { Boli- } \\
\text { via }\end{array}$ & $\begin{array}{c}\text { Bra- } \\
\text { sil }\end{array}$ & $\begin{array}{c}\text { Colom- } \\
\text { bia }\end{array}$ & $\begin{array}{c}\text { Costa } \\
\text { Rica }\end{array}$ & Chile & $\begin{array}{c}\text { Ecua- } \\
\text { dor }\end{array}$ & $\begin{array}{c}\text { Guate- } \\
\text { mala }\end{array}$ & $\begin{array}{c}\text { Méxi- } \\
\text { co }\end{array}$ & $\begin{array}{l}\text { Pana- } \\
\text { má }\end{array}$ & $\begin{array}{l}\text { Para- } \\
\text { guay }\end{array}$ & Perú & $\begin{array}{l}\text { Uru- } \\
\text { guay }\end{array}$ & $\begin{array}{l}\text { Vene- } \\
\text { zuela }\end{array}$ \\
\hline 14839 & 100 & 1200 & 794 & 1000 & 1200 & 1000 & 1200 & 1200 & 1000 & 1200 & 1000 & 600 & 1045 & 1200 & 1200 \\
\hline
\end{tabular}

Tomando todo en consideración, ¿diría usted que sus padres vivían mejor, igual o peor que como usted vive hoy?

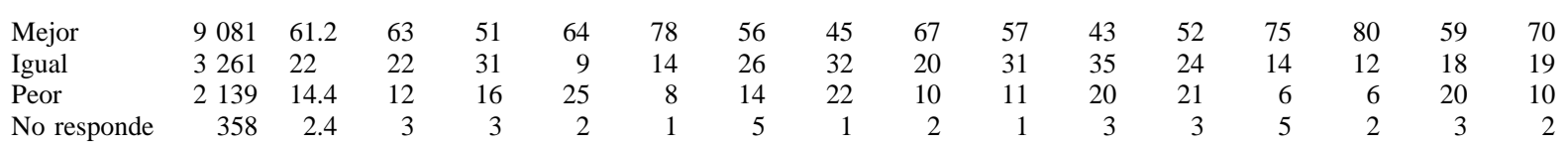

Y respecto a sus hijos, ¿cree usted que vivirán mejor, igual o peor que como usted vive hoy?

\begin{tabular}{|c|c|c|c|c|c|c|c|c|c|c|c|c|c|c|c|}
\hline Mejor & 6843 & 46.1 & 43 & 56 & 58 & 36 & 52 & 61 & 34 & 51 & 30 & 48 & 48 & 37 & 46 \\
\hline Igual & 3071 & 20.7 & 22 & 20 & 12 & 21 & 25 & 22 & 21 & 23 & 23 & 20 & 26 & 19 & 22 \\
\hline Peor & 3261 & 2 & 20 & 13 & 21 & 38 & 11 & 11 & 29 & 17 & 41 & 21 & 13 & 26 & 19 \\
\hline No responde & 1664 & 11.2 & 16 & 11 & 9 & 6 & 12 & 7 & 16 & 8 & 6 & 12 & 13 & 19 & 13 \\
\hline
\end{tabular}

Fuente: Mirror on the Americas Poll (1999), Wall Street Journal Interactive Edition.

$\square$ El presente artículo fue preparado para el Banco Mundial y financiado por él. Agradezco a Guillemo Perry por haberme solicitado la elaboración de este trabajo, a Jorge Domínguez, Nora Lustig, Norman Hicks, Bill Maloney, Guillermo Perry, Martín Rama, Guilherme Sedlacek, Luis Serven y Mariano Tommasi por sus inapreciables observaciones sobre una versión preliminar anterior. Vladunur Kliouev se desempeñó como asistente de investigación especializado. Ninguna de estas personas, y menos aun el Banco Mundial, es responsable de las opiniones aquí vertidas. 
América Latina (14 países): Respuestas a una encuesta sobre aspectos vinculados con el seguro social, por categoría socioeconómica ${ }^{a}$

(En porcentaje, a menos que se indique otra cosa)

\begin{tabular}{|c|c|c|c|c|c|c|c|c|c|c|c|c|c|c|c|c|c|c|}
\hline & \multicolumn{2}{|c|}{ Muestra total } & \multicolumn{3}{|c|}{ Edad } & \multicolumn{6}{|c|}{ Empleo } & \multicolumn{4}{|c|}{ Educación } & \multicolumn{3}{|c|}{ Ingreso } \\
\hline & $\mathrm{N}^{0}$ & $\%$ & $\begin{array}{l}18- \\
29\end{array}$ & $\begin{array}{c}30- \\
49\end{array}$ & $50+$ & $\begin{array}{l}\text { Autó- } \\
\text { nomo }\end{array}$ & Gob. & $\begin{array}{l}\text { Sect. } \\
\text { priv. }\end{array}$ & $\begin{array}{l}\text { Des- } \\
\text { emp. }\end{array}$ & $\begin{array}{l}\text { Reti- } \\
\text { rado }\end{array}$ & $\begin{array}{c}\text { Ama } \\
\text { de } \\
\text { casa }\end{array}$ & Estud. & Prim. & Sec. & Univ. & Alto & Medio & Bajo \\
\hline \multicolumn{19}{|c|}{ Seguro de desempleo } \\
\hline No responde & 551 & 3.7 & 3 & 4 & 4 & 4 & 5 & 3 & 3 & 4 & 4 & 3 & 4 & 3 & 4 & 4 & 4 & 3 \\
\hline Gastar más & 10088 & 73.4 & 74 & 73 & 73 & 74 & 69 & 74 & 80 & 74 & 73 & 74 & 74 & 75 & 71 & 72 & 73 & 74 \\
\hline Gastar menos & 2543 & 17.1 & 18 & 18 & 16 & 17 & 19 & 17 & 13 & 16 & 17 & 19 & 16 & 16 & 19 & 19 & 17 & 17 \\
\hline No sabe & 857 & 5.8 & 5 & 5 & 7 & 5 & 7 & 6 & 3 & 6 & 7 & 5 & 7 & 5 & 6 & 4 & 6 & 6 \\
\hline \multicolumn{19}{|l|}{ Pensiones } \\
\hline No responde & 172 & 1.2 & 1 & 1 & 1 & 1 & 2 & 1 & 1 & 1 & 1 & 1 & 1 & 1 & 1 & 2 & 1 & 1 \\
\hline Gastar más & 12426 & 83.7 & 83 & 83 & 86 & 83 & 84 & 84 & 88 & 88 & 84 & 82 & 83 & 85 & 83 & 83 & 85 & 83 \\
\hline Gastar menos & 1861 & 12.5 & 13 & 13 & 10 & 13 & 12 & 13 & 9 & 9 & 12 & 15 & 13 & 12 & 14 & 14 & 11 & 13 \\
\hline No sabe & 380 & 2.6 & 3 & 3 & 3 & 3 & 2 & 2 & 1 & 2 & 3 & 2 & 3 & 2 & 2 & 2 & 2 & 3 \\
\hline \multicolumn{19}{|c|}{ Defensa y fuerzas armadas } \\
\hline No responde & 623 & 4.2 & 4 & 5 & 5 & 4 & 6 & 3 & 3 & 5 & 4 & 3 & 4 & 4 & 5 & 5 & 5 & 3 \\
\hline Gastar más & 4810 & 32.4 & 33 & 31 & 34 & 34 & 28 & 29 & 36 & 33 & 35 & 32 & 37 & 33 & 27 & 32 & 31 & 34 \\
\hline Gastar menos & 8359 & 56.3 & 58 & 57 & 53 & 56 & 59 & 60 & 56 & 54 & 52 & 60 & 50 & 57 & 62 & 58 & 56 & 57 \\
\hline No sabe & 1047 & 7.1 & 5 & 7 & 9 & 6 & 7 & 7 & 5 & 8 & 9 & 5 & 8 & 7 & 7 & 6 & 8 & 7 \\
\hline
\end{tabular}

Fuente: Mirror on the Americas Poll (1999), Wall Street Journal Interactive Edition.

a Texto de la pregunta: “Podría decirme si cree que en su país sería mejor gastar más o menos en cada uno de los siguientes rubros?"

variaba muy poco con el nivel de ingreso, educación y tipo de ocupación de los encuestados (cuadro 2). Como era de prever, la demanda de seguro social tiende a ser más alta en los países en que impera un mayor pesimismo respecto al futuro. Pero hay excepciones interesantes. En México, las demandas de mayor gasto en seguro social son débiles pese a un alto nivel de pesimismo sobre las perspectivas de la próxima generación. En Chile, en tanto, donde las expectativas son razonablemente auspiciosas, el porcentaje de encuestados que favorece un mayor gasto llegaba a $85 \%$ en el caso del seguro de desempleo y a $93 \%$ en el caso de las pensiones.

¿Significan algo estas cifras? Un indicio de que sí lo hacen proviene de las respuestas a otras preguntas de la encuesta. Por ejemplo, cuando los mismos individuos eran interrogados acerca de la defensa nacional y las fuerzas armadas, menos de un tercio contestaba que desearía que se incrementara el gasto en ellas (cuadro 2). Esto demuestra que los encuestados hacían una clara distinción entre la seguridad económica y la seguridad nacional, y que situaban a la primera muy por encima de esta última. Otro indicio proviene de comparar resultados de encuestas similares en otros entornos. Cuando las encuestas de esta índole se realizan en países industrializados, la proporción de encuestados que favorece un mayor gasto en pensiones y seguro de desempleo tiende a ser notoriamente menor. Además, las proporciones varían apreciablemente según los niveles de ingreso. ${ }^{1}$ El New York Times destacaba hace poco un ejemplo patético en Brasil, donde no menos de un millón de personas (uno de cada 160 brasileños) competían en agosto de 1999 por 10000 empleos de oficina en el Banco do Brasil, una institución administrada por el gobierno que "paga los sueldos íntegros y oportunamente" y ofrece un seguro de salud integral y beneficios previsionales. "Necesito estabilidad en mi vida", habría declarado una candidata de 23 años al preguntársele por qué postulaba a un empleo en que ganaba menos que en la ocupación que tenía (Romero, 1999). El hecho de ocuparse de la inseguridad económica parece ser una parte clave de la agenda inconclusa de las reformas latinoamericanas.

${ }^{1}$ Véanse algunos datos comparativos en Taylor-Gooby (1989). 
¿Cómo avanzan las autoridades desde aquí? El primer paso es conocer las causas fundamentales de la inseguridad económica. En el presente artículo se destaca el papel de tres conjuntos de factores decisivos que contribuyen a ella. Primero, debemos comenzar por el trauma de los años ochenta. La profunda recesión que experimentó la mayoría de los países de la región al término de la crisis de la deuda recuerda, en cierta forma, la Gran Depresión que afectó a los Estados Unidos durante los años treinta. Aunque esa crisis provocó una caída más abrupta de los ingresos, la recuperación posterior también fue más rápida. En los Estados Unidos, las penurias causadas por la Gran Depresión, y especialmente las pérdidas sufridas por las clases medias, estimularon la creación de un conjunto de programas gubernamentales - conocidos colectivamente como el Nuevo Trato- que ampliaron sobremanera el papel del gobierno, establecieron redes de seguridad social y brindaron seguro social. En América Latina, el resultado final de la crisis de la deuda fue una serie de reformas que en realidad sirvieron para debilitar las instituciones de seguro social. El empleo se tornó en general menos estable y las redes de seguridad proporcionadas por el sector público se debilitaron.

Segundo, al entrar América Latina en los años noventa se encontró en un mundo de gran volatilidad macroeconómica, impulsada en parte por flujos de capital erráticos o al menos magnificada por ellos. La difusión de los mercados financieros internacionales y la acogida entusiasta que les dio la región dejaron a la política macroeconómica dependiente (y a menudo rehén) de los caprichos de los inversionistas de corto plazo. Instrumentos claves como la política fiscal y el tipo de cambio fueron sobrepasados por la necesidad de gestionar flujos de capital y ya no pudieron destinarse a la estabilidad interna. La política macroeconómica se divorció cada vez más de la economía real, lo que exacerbó la volatilidad de los resultados económicos tanto en el tiempo como entre los hogares.

Tercero, una deficiencia clave en América Latina es que hasta ahora las instituciones sociales y políticas no se han sensibilizado adecuadamente al clamor por una mayor seguridad económica. Cabe recordar que los Estados han eludido, más que asumido, las nuevas responsabilidades que exige la gestión del riesgo en sociedades orientadas al mercado. Pero el problema trasciende los gobiernos. Los sistemas políticos en su conjunto no han creado mecanismos viables de participación: los parlamentos nacionales se han fragmentado y no son representativos, y los partidos políticos son débiles. Los sindicatos no han sido capaces de desarrollar una estrategia adecuada y global para encarar la inseguridad en el empleo y han perdido afiliados. Y la monopolización de los debates de política en torno a una visión estrecha de la política de desarrollo, por las líneas del Consenso de Washington y notoriamente restringida por los "requisitos" de la integración económica mundial, ha impedido el surgimiento de una visión alternativa (o al menos complementaria) de una reforma económica impulsada por los intereses locales y las aspiraciones nacionales.

Examinaré estos aspectos y sus implicaciones de política en el resto del artículo. Pero cabe formular de partida una advertencia crucial. Este artículo no está centrado en los pobres y los más vulnerables per se. No me ocupo aquí de políticas contra la pobreza, ni analizo cómo reducir la vulnerabilidad de los pobres a la volatilidad y las perturbaciones (shocks). ${ }^{2}$ Los pobres de América Latina han sido siempre excluidos y vulnerables. Lo que parece ser novedoso es que el temor a la movilidad descendente afecta ahora también a gran parte de las clases medias. La encuesta mencionada más atrás revela que en algunos de los países más grandes de la región —en particular Argentina, Brasil, México y Venezuela- los grupos de ingresos medios están más pesimistas sobre el futuro de sus hijos que los grupos de bajos ingresos. De hecho, esto es lo que otorga a la demanda de "protección social" su notoriedad política en la región. Me centraré en esta noción más amplia de inseguridad económica y sus consecuencias.

Por último, debo destacar que la finalidad de este artículo es estimular el debate, sugerir hipótesis y diseñar una agenda para investigaciones futuras, como también lo es presentar argumentos concretos con datos que los respalden. Muchos de los argumentos que expongo siguen siendo especulativos. Las "pruebas" empíricas que presento son sugerentes y no definitivas. Pero el artículo habrá logrado su objetivo en la medida en que sirva para abrir nuevas líneas de investigación.

\footnotetext{
2 Véase un buen conjunto de ensayos sobre estos temas en Lustig, ed. (1995).
} 


\section{II}

\section{El trauma de los años ochenta}

La crisis de la deuda de 1982 sumió a América Latina en una recesión profunda y prolongada. El gráfico 1 muestra el índice del ingreso per cápita en los principales países de la región, comparando su experiencia con la de los Estados Unidos durante la Gran Depresión. En los Estados Unidos, los ingresos declinaron $35 \%$ en promedio entre 1929 y 1933 y el desempleo llegó a un máximo de $25 \%$ en este último año. Como se indica en el gráfico, la declinación de los ingresos reales (y el aumento del desempleo) no fue tan abrupta en América Latina después de 1981: alrededor de $20 \%$ en Argentina, Chile, México y Venezuela, y de $10 \%$ en Brasil. Entre los países principales, sólo Perú experimentó (gracias a las políticas desastrosas del Presidente García) un colapso del ingreso de la misma magnitud que los Estados Unidos en la Gran Depresión. Sin embargo, con la notable excepción de Chile, la recuperación en América Latina fue también más gradual. En los Estados Unidos, el ingreso per cápita tardó 10 años en recuperar su nivel previo a la crisis. En Argentina y Brasil tardó 12 y 13 años, respectivamente, y en México, Perú y Venezuela los ingresos per cápita en 1997, último año con estimaciones disponibles sobre el ingreso nacional (Banco Mundial, 1999), todavía eran inferiores a los de 1981. Además, la economía de los Estados Unidos, impulsada en parte por la Segunda Guerra Mundial, experimentó una expansión mucho más rápida en los años cuarenta que en los veinte. La tasa de crecimiento de América Latina durante los años noventa no logró equiparar las cifras de los años sesenta y setenta.

Los Estados Unidos respondieron a la Gran Depresión con una serie de importantes innovaciones institucionales que ampliaron sobremanera el papel del gobierno en la economía y representaron en buena medida una ruptura violenta con el pasado. Muchas de estas innovaciones se tradujeron en seguro social (Bordo, Goldin y White, eds., 1998, p. 6): la seguridad social, la compensación por desempleo, las obras públicas, la propiedad pública, la garantía de depósitos y la legislación favorable a los sindicatos figuraban entre los nuevos mecanismos creados para encarar las deficiencias que se advertían en el mercado privado. Como señala Jacoby (1998), antes de la Gran Depresión las

GRAFICO 1

Comparación entre América Latina después de 1981 y los Estados Unidos en la Gran Depresión: Declinación de los ingresos reales per cápita

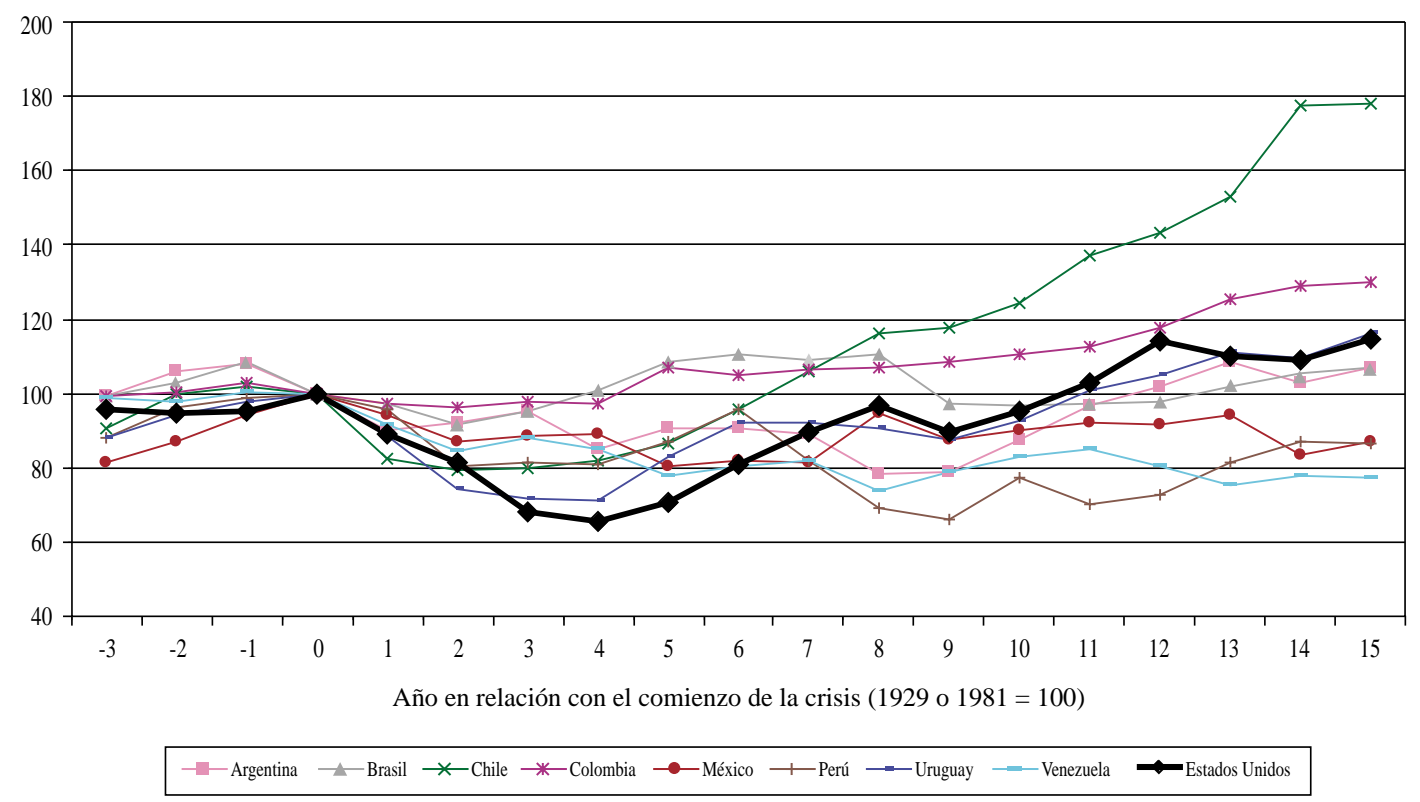


clases medias podían en general autoasegurarse o comprar seguros a intermediarios privados. Al colapsar estas formas de seguro privado, las clases medias utilizaron su considerable peso político para ampliar el seguro social y crear lo que posteriormente se denominaría el Estado benefactor.

La Gran Depresión tuvo dos efectos: primero, minó la confianza de la clase media en el sistema privado para manejar los riesgos del mercado laboral; el colapso del capitalismo de bienestar, sumado a despidos masivos y quiebras bancarias, creó una crisis de confianza que llevó a la clase media estadounidense a movilizarse en búsqueda de alternativas. Segundo, hizo que la clase media percibiera como precaria su condición social; la movilidad descendente real o en ciernes disminuyó la distancia social entre la clase media y las que la seguían, hizo más probables las alianzas entre clases y debilitó la resistencia a los programas redistributivos que pudieran beneficiar a los que descendían... En suma, las experiencias de los años treinta y cuarenta inclinaron a la clase media estadounidense a favorecer la solidaridad social en vez del individualismo duro, un cambio que promovió el Estado benefactor, la educación pública y otras formas de gasto del gobierno (Jacoby, 1998, pp. 29-31).

Nótese el paralelismo con la experiencia latinoamericana después de la crisis de la deuda. Tal como en el caso de los Estados Unidos, la crisis de los años ochenta ejerció grandes presiones sobre los mecanismos de seguro privado en América Latina. Por ejemplo, Glewwe y Hall (1998) observan en su análisis de Perú que las redes de transferencia entre hogares colapsaron casi por completo durante el segundo lustro de los años ochenta. Dado que los hogares que hacen las transferencias también sufren durante las grandes crisis, los sistemas privados de apoyo al ingreso tienden a no ser muy flexibles frente a las macroperturbaciones. Y una consecuencia de la crisis generalizada fue que, según se señaló en la introducción, el seguro social pasó a ser asimismo una preocupación de la clase media en América Latina.

Pero también hubo un respaldo ideológico al crecimiento de los programas gubernamentales en los Estados Unidos. Rockoff (1998) ha sostenido que el cambio de actitudes frente al papel del gobierno se facilitó en los Estados Unidos debido a que hubo un cambio ideológico entre los economistas — del laissez-faire al intervencionismo- que se remonta al menos a una década antes de la Gran Depresión. Mientras que los macroeconomistas tendían a ser conservadores, los microeconomistas abogaban por una larga lista de reformas como el salario mínimo, las bolsas de empleo, las pensiones de vejez, los servicios de utilidad pública regionales de propiedad estatal, etc. (ibid. p. 134). De aquí que la ideología y los intereses coincidieran en espolear la adopción de programas de seguro social.

En cuanto al papel del gobierno, América Latina entró a los años ochenta desde una posición estratégica muy diferente a la de los Estados Unidos al ingresar a los años treinta. La mayoría de los países de la región se había industrializado merced a restricciones comerciales impuestas por el gobierno, las empresas públicas habían pasado a ser una cosa corriente, y los déficit fiscales y la mala gestión macroeconómica eran las causas próximas de la crisis de la deuda. Y tal como en el caso de los Estados Unidos, la opinión académica había cambiado considerablemente durante los años setenta, pero esta vez hacia favorecer los mercados y no la intervención del gobierno.

Las reformas que América Latina adoptó en los años ochenta, y con posterioridad, se destinaron en consecuencia a realzar el radio de acción del mercado y a frenar el del gobierno. La privatización, la desregulación, la liberalización comercial y la liberalización financiera fueron elementos claves del Consenso de Washington. Las encuestas de opinión pública, como las ya citadas, muestran en general que la mayoría de los latinoamericanos prefieren los mercados y el sistema de empresa privada al control del gobierno. Sin embargo, lo que es importante desde nuestra perspectiva es la ausencia completa en la agenda del Consenso de Washington de recetas dirigidas a combatir la inseguridad económica.

Esto es sorprendente, en especial porque muchas de las reformas en pro del mercado tenían el efecto predecible de incrementar el riesgo para los trabajadores y hogares. La privatización, la desregulación y la liberalización comercial entrañaban la reestructuración de la economía y un mayor riesgo de pérdida de ocupaciones, al menos en el corto plazo. La reducción del sector público significaba menores oportunidades de lograr un empleo público relativamente seguro. Era de suponer que la liberalización financiera generaría volatilidad en el entorno económico. La mayor movilidad del capital implicaba desplazar el riesgo-país idiosincrásico desde el capital móvil a la mano de obra inmóvil. Sólo últimamente se ha venido a reconocer la importancia de tales efectos.

Por lo tanto, podemos suponer que la inseguridad económica generada por la prolongada crisis de la deuda sólo se vio amplificada por las reformas orien- 
tadas al mercado que todos los países de la región adoptaron en definitiva, sin instituir programas complementarios de seguro social. Mientras que en los Estados Unidos la respuesta a la Gran Depresión fue el fortalecimiento significativo de la protección social, en América Latina la respuesta a la crisis de la deuda fue el debilitamiento del seguro social frente a mayores riesgos en el mercado laboral.

\section{III}

\section{La declinación de la seguridad en el empleo}

Si bien se podría haber esperado que muchas de las reformas emprendidas en América Latina aumentaran la inseguridad en el empleo, al menos en el corto plazo, no es fácil conseguir datos directos que avalen esta suposición. Las medidas de desplazamiento involuntario del empleo no son muchas, y en todo caso están contaminadas por las respuestas conductuales que genera la inseguridad económica: los trabajadores que se sienten menos seguros son más propensos a aceptar reducciones salariales o a hacer otras concesiones para evitar la pérdida de sus empleos. Además, no ha habido muchos cambios en la legislación formal sobre protección del empleo, pese a que se ha hablado mucho sobre la necesidad de volver más "flexibles" los mercados laborales (Márquez y Pages, 1998). No obstante, los datos disponibles sí sugieren que la proporción de trabajadores con empleos "seguros" ha declinado en casi todos los países de la región con datos al respecto.

Un indicio de ello es la violenta reducción de la densidad de los sindicatos desde los años ochenta en todos los países, salvo Chile. Esto es importante puesto que negociar para obtener mayor seguridad en el empleo en nombre de sus afiliados es una función clave de los sindicatos. El cuadro 3 presenta estadísticas de la Organización Internacional del Trabajo (оIт) sobre la afiliación sindical y la densidad sindical en 10 países latinoamericanos. Cuando se puede establecer una comparación entre los años ochenta y noventa, las cifras revelan habitualmente una brusca declinación. En Argentina, por ejemplo, el porcentaje de la mano de obra no agrícola representada por sindicatos cayó de $49 \%$ en 1986 a $25 \%$ en 1995. En México, la cifra correspondiente disminuyó (si ha de creerse en las estadísticas) de $54 \%$ a $31 \%$ en el lapso de dos años (1989 a 1991). Chile, donde el término del régimen de Pinochet y la transición a la democracia produjo un brusco aumento inicial de la afiliación y densidad sindical, es la única excepción a la regla. Sin embargo, incluso en Chile las cifras más recientes indican que las tasas de afiliación han disminuido desde comienzos de los años noventa, y actualmente han retrocedido a los niveles previos al regreso de la democracia. ${ }^{3}$

El cuadro 3 muestra asimismo otro indicador de inseguridad en el empleo: la proporción de trabajadores que no están "protegidos" por contratos escritos formales o incluidos en los programas de prestaciones sociales. La definición de empleo desprotegido, tomada de la oIт (1999), es algo escurridiza, y se refiere a cosas diferentes en países diferentes. Por ejemplo, en Argentina las cifras se refieren a los empleados del sector privado sin contrato escrito como proporción del empleo privado total en el Gran Buenos Aires. En Bolivia, las cifras se refieren a aquellos que no están cubiertos por la legislación laboral y social, expresados como proporción del total del empleo asalariado. En Brasil, las cifras (tomadas de Ferreira y Paes de Barros, 1999) corresponden a los empleados sin carteira expresados como una fracción de todos los empleados asalariados y trabajadores autónomos.

En los siete países donde es posible comparar entre dos momentos en el tiempo, las cifras revelan un salto ascendente del empleo "desprotegido": de $22 \%$ a $34 \%$ en Argentina, de $64 \%$ a $69 \%$ en Brasil, de $44 \%$ a $50 \%$ en México. Esta vez Chile no es la excepción a la tendencia (con un incremento de $17 \%$ a $22 \%$ ). Nótese que estas proporciones no pueden compararse entre países puesto que las muestras cubiertas varían considerablemente, y las proporciones absolutas en sí no son muy significativas (a diferencia de los cambios en ellas). Puesto que los denominadores suelen incluir a los trabajadores más privilegiados (los de las zonas urbanas o los asalariados), las proporciones mencionadas subestiman en la mayoría de los casos la verdadera proporción de trabajadores desprotegidos. La

\footnotetext{
${ }^{3}$ Cifras del Ministerio del Trabajo de Chile, publicadas en The Economist Intelligence Unit, 1998.
} 
América Latina (10 países): Indicadores de seguridad en el empleo

\begin{tabular}{|c|c|c|c|c|c|c|}
\hline \multirow{2}{*}{ Argentina } & \multicolumn{2}{|c|}{$\begin{array}{l}\text { Afiliación sindical } \\
\text { (En miles) }\end{array}$} & \multicolumn{2}{|c|}{$\begin{array}{c}\text { Densidad sindical } \\
\text { (Como porcentaje de la } \\
\text { mano de obra no agrícola) }\end{array}$} & \multicolumn{2}{|c|}{$\begin{array}{c}\text { Empleo "desprotegido"a } \\
\text { (Como porcentaje } \\
\text { de los empleados) }\end{array}$} \\
\hline & 1986 & 3262 & 1986 & 48.7 & 1990 & 21.7 \\
\hline & 1995 & 3200 & 1995 & 25.4 & 1996 & 34 \\
\hline \multirow[t]{2}{*}{ Bolivia } & 1994 & 276 & 1994 & 16.4 & 1991 & 28 \\
\hline & & & & & 1997 & 34.8 \\
\hline \multirow[t]{2}{*}{ Brasil } & 1991 & 15205 & 1991 & 32.1 & 1985 & 63.6 \\
\hline & & & & & 1996 & 68.5 \\
\hline \multirow[t]{2}{*}{ Chile } & 1985 & 361 & 1985 & 11.6 & 1990 & 17 \\
\hline & 1993 & 684 & 1993 & 15.9 & 1996 & 22.3 \\
\hline \multirow{2}{*}{ Colombia } & 1985 & 877 & 1985 & 11.2 & & \\
\hline & 1995 & 840 & 1995 & 7.0 & & \\
\hline \multirow[t]{2}{*}{ El Salvador } & 1985 & 79 & 1985 & 7.9 & 1994 & 59.1 \\
\hline & 1995 & 103 & 1995 & 7.2 & 1997 & 61.3 \\
\hline \multirow[t]{2}{*}{ México } & 1989 & 9500 & 1989 & 54.1 & 1990 & 43.4 \\
\hline & 1991 & 7000 & 1991 & 31.0 & 1997 & 49.6 \\
\hline \multirow[t]{2}{*}{ Perú } & 1991 & 442 & 1991 & 7.5 & 1990 & 25.5 \\
\hline & & & & & 1996 & 34.1 \\
\hline \multirow[t]{2}{*}{ Uruguay } & 1990 & 222 & 1990 & 19.9 & & \\
\hline & 1993 & 151 & 1993 & 11.6 & & \\
\hline \multirow{2}{*}{ Venezuela } & 1988 & 1700 & 1988 & 25.9 & & \\
\hline & 1995 & 1153 & 1995 & 14.9 & & \\
\hline
\end{tabular}

Fuente: OIT (1997, cuadros 1.1 y 1.2); OIT (1999, cuadro 7); Ferreira y Paes de Barros (1999, cuadro 1).

a El término empleo "desprotegido" se refiere a la proporción de empleados sin contrato escrito o prestaciones sociales, según el país. Los empleados son del sector privado o tienen empleo urbano. Véase ort (1999, cuadro 7) para las fuentes originales y mayores detalles.

afirmación tan repetida de que la economía informal representa el $80 \%$ de los nuevos empleos creados en América Latina en las dos últimas décadas (véase ort, 1999) ofrece una perspectiva que complementa estas observaciones. ${ }^{4,5}$

\footnotetext{
${ }^{4}$ Sigue siendo debatible en qué medida la menor participación del empleo en el sector formal es el resultado de una legislación restrictiva en materia de empleo, tal como el salario mínimo y las prestaciones legales. Amadeo y Camargo (1997) sostienen, en el contexto brasileño, que tal legislación explica sólo una pequeña parte de la situación. Pessino (1997) ofrece otra perspectiva respecto a Argentina.

${ }^{5}$ Nótese que el empleo en el sector informal, pese a niveles generalmente más reducidos de seguridad en el empleo, no implica necesariamente peores resultados para los trabajadores. En muchos casos, los trabajadores preferirían la informalidad para evitar el pago de impuestos a la renta.
}

Puesto que la propia legislación no ha cambiado gran cosa, estas tendencias tienen que interpretarse como las respuestas endógenas de la economía a las perturbaciones conjuntas de la crisis de la deuda y la reforma estructural. En Chile, por ejemplo, el período posterior a la crisis de la deuda ha presentado históricamente altos niveles de rotación laboral. Además, la liberalización comercial ha causado la expansión de actividades (en particular, silvicultura y agricultura) en que el empleo con contrato a largo plazo es poco común y predomina más el empleo por cuenta propia, a diferencia de lo que sucede en las actividades tradicionales (como la minería del cobre y las manufacturas). La expansión de las exportaciones ha estado vinculada también con un aumento de la subcontratación, que generalmente traslada el riesgo a la pequeña empresa 
y a los trabajadores por cuenta propia. En la silvicultura, un desempeño exportador impresionante ha ido acompañado de un tipo de organización laboral caracterizado por una elevada proporción de actividades de subcontratación y por inestabilidad en el empleo (OIT, 1998). En Brasil, la rotación laboral sigue siendo bastante alta comparada con los estándares europeos o incluso estadounidenses, una situación que Amadeo y Camargo (1997) caracterizan como un caso de flexibilidad "excesiva" del empleo.

¿La declinación manifiesta de la protección del empleo se ha compensado con menores tasas de desempleo global? La literatura empírica sobre la relación entre costos por terminación de contrato y tasas de desempleo no arroja conclusiones firmes. Los datos nacionales sugieren generalmente que los efectos de primer orden de la protección del empleo son distributivos: los beneficiarios tienden a ser hombres más viejos en desmedro de mujeres más jóvenes. Pero la relajación de la legislación de protección del empleo parece tener pocos efectos sobre el nivel de empleo global. Los escasos datos al respecto provenientes de América Latina son compatibles con esas conclusiones (Márquez y Pages, 1998).

El cuadro 4 presenta las tasas de desempleo en 16 países latinoamericanos, correspondientes a tres subperíodos posteriores a 1981 (1981-1988, 1989-1993 y 1994-1998). En la mayoría de los países, el patrón de desempleo tiene forma de U. Los primeros años tras la crisis de la deuda fueron, en general, de alto desempleo. Este disminuyó a fines de los años ochenta, pero posteriormente se ha elevado desde mediados de los noventa. Brasil, México, Uruguay y Venezuela presentan este patrón. Pero también hay excepciones. En Chile, el desempleo se ha mantenido muy por debajo de los niveles registrados en la primera mitad de los años ochenta. En Argentina, ha aumentado en forma

\begin{tabular}{lccr} 
CUADRO 4 & $\begin{array}{l}\text { América Latina (16 países): Tasas } \\
\text { de desempleo } \\
\text { (En porcentaje) }\end{array}$ & \\
& & & \\
\hline & $1981-1988$ & $1989-1993$ & $1994-1998$ \\
\hline Argentina & 5.4 & 7.6 & 15.3 \\
Bolivia & 7.6 & 6.9 & 3.6 \\
Brasil & 5.6 & 4.7 & 5.7 \\
Chile & 14.9 & 7.2 & 7.6 \\
Colombia & 11.6 & 9.9 & 10.4 \\
Costa Rica & 6.2 & 4.4 & 5.4 \\
Ecuador & 8.2 & 8.1 & 8.8 \\
El Salvador & 9.4 & 8.5 & 7.2 \\
Guatemala & 9.1 & 4.1 & 4.0 \\
Honduras & 10.3 & 7.1 & 5.6 \\
México & 4.0 & 2.9 & 4.8 \\
Nicaragua & 13.0 & 14.7 & 16.5 \\
Paraguay & 5.6 & 5.6 & 6.0 \\
Perú & 6.9 & 8.3 & 7.8 \\
Uruguay & 11.3 & 8.8 & 10.8 \\
Venezuela & 10.4 & 8.4 & 10.5 \\
\hline
\end{tabular}

Fuente: Banco Interamericano de Desarrollo (BID, s/f).

más o menos sostenida desde principios de los años ochenta para los trabajadores con cualquier nivel de especialización (Pessino, 1997). Llama la atención que la mitad de los países del cuadro (ocho de dieciséis) tuvieron tasas de desempleo más elevadas en 19941998 que en 1981-1988 (Argentina, Brasil, Ecuador, México, Nicaragua, Perú, Paraguay y Venezuela).

Por lo tanto, la menor protección del empleo se acompañó de niveles de desempleo crecientes durante los años noventa en la mayoría de los países de la región. Aunque es posible que el desempleo se hubiera elevado más si los sindicatos no hubieran perdido afiliados y no se hubieran debilitado otras protecciones del empleo, los datos internacionales sugieren que éste no es un escenario muy probable. Los riesgos de pérdida del empleo seguido de un período de desempleo parecen haber aumentado claramente.

\section{IV}

\section{La volatilidad macroeconómica y su relación con el ingreso de los hogares: una descomposición}

Aunque el temor a la reducción drástica del ingreso asociada a la pérdida del empleo y el desempleo es un componente importante de la inseguridad económica, otro componente es la mera volatilidad de los ingresos de los hogares. Según lo han destacado Gavin y Hausmann (1996) en sus escritos, América Latina es 
una región volátil, donde la desviación estándar de las tasas de crecimiento del producto nacional bruto (PNB) tiende a ser, en general, alrededor del doble del nivel observado en las economías industrializadas. En cada hogar, lo que interesa es la volatilidad de su propia corriente de ingresos. Si bien, por definición, no todos los hogares pueden protegerse con éxito de la volatilidad media de la economía (captada por los movimientos del PNB agregado), la distribución de la incertidumbre entre los hogares sí depende de la medida en que los riesgos de los hogares varían con el producto nacional. ${ }^{6}$

Podemos expresar la relación entre la volatilidad del ingreso del hogar y del ingreso nacional utilizando una descomposición simple basada en la identidad:

$$
d \ln y_{i t} \equiv d \ln y_{t}+\left(d \ln y_{i t}-d \ln y_{t}\right)
$$

donde $\mathrm{y}_{i t}$ e $y_{t}$ son los ingresos del hogar y nacional en el tiempo $t, \mathrm{y} d \ln y_{i t} \mathrm{y} d \ln y_{t}$ son la tasa de crecimiento del ingreso del iésimo hogar y del PNB, respectivamente. Definamos las tasas de crecimiento del hogar y nacional como:

$$
\begin{aligned}
& d \ln y_{i t}=\delta_{i t} \\
& d \ln y_{t}=\delta_{t}
\end{aligned}
$$

Además, que la tasa de crecimiento del ingreso del hogar en relación con el promedio nacional esté dada por:

$$
\left(d \ln y_{i t}-d \ln y_{t}\right)=\rho_{i t}
$$

Ahora, podemos descomponer la volatilidad del crecimiento del ingreso del iésimo hogar en tres términos separados.

$$
\sigma_{\delta_{i}}^{2}=\sigma_{\delta}^{2}+\sigma_{\rho_{i}}^{2}+2 \operatorname{cov}\left(\rho_{i t}, \delta_{t}\right)
$$

El primer término representa la volatilidad de la economía nacional $\left(\sigma_{\delta}^{2}\right)$. Este término capta las macroperturbaciones a que está sujeta la economía y es la volatilidad en que se centra el trabajo de Gavin y Hausmann (1996). El segundo término es la volatilidad de los ingresos relativos del hogar $\left(\sigma_{\rho_{i}}^{2}\right.$. Éste capta las

\footnotetext{
${ }^{6}$ Para los fines de este análisis, el ingreso nacional y el PNB son intercambiables.
}

perturbaciones puramente idiosincrásicas que golpean un hogar determinado. Por último, el tercer término es la covarianza entre las tasas de crecimiento del PNB y los ingresos relativos del hogar $\left(\operatorname{cov}\left(\rho_{i t}, \delta_{t}\right)\right)$. Este término será positivo cada vez que el ingreso relativo del hogar sea procíclico, es decir, cuando el ingreso del hogar crece más rápido que el promedio en épocas propicias para la economía nacional y más lento que el promedio en épocas adversas. Por cierto que el tercer término no puede tener el mismo signo para todos los hogares de la economía. Lustig (1999) cita estudios que demuestran que por cada punto porcentual en que cae el crecimiento, la pobreza aumenta $2 \%$. Si los pobres son más vulnerables a las recesiones económicas, como indican estos estudios, el tercer término será positivo para los hogares situados al pie de la escala de distribución del ingreso y negativo para los hogares situados en la cima.

La descomposición sirve para organizar nuestro pensamiento sobre cómo abordar mejor la incertidumbre a nivel del hogar. Destaca tres fuentes de incertidumbre con tres clases diferentes de implicaciones en materia de políticas. Si la mayor parte de la incertidumbre está a nivel macroeconómico, mejorar la calidad de las políticas macroeconómicas sería el método más directo y efectivo de reducir el riesgo del hogar. En cambio, si la mayor parte de ella es idiosincrásica, específica de cada hogar, lo que se necesita es simplemente un seguro (suministrado por el sector privado o el gobierno). Y si parte considerable de la incertidumbre se origina en la excesiva susceptibilidad de determinados hogares a las recesiones macroeconómicas, entonces habrá que identificar esos hogares y asegurarse de que los mecanismos de transferencia sean i) focalizados en forma adecuada, y ii) resistentes a las macroperturbaciones. ${ }^{7}$

Para efectuar esta descomposición se requieren datos de paneles repetidos de hogares que no existen para muchos países. Las encuestas de medición de niveles de vida de Perú sí los ofrecen. Glewwe y Hall (1998) los han utilizado con el fin de identificar los hogares que son más vulnerables a las perturbaciones.

Con el fin de mostrar cómo puede utilizarse la descomposición, realizaré un ejercicio muy burdo basado en datos sobre salarios reales medios de fácil obtención. El ejercicio consiste en hacer cálculos

\footnotetext{
7 Véase Lustig (1999), en particular sobre el diseño de medidas en favor de los pobres ante perturbaciones adversas. Lustig aboga por la institución de redes de seguridad anticíclicas para proteger a los pobres de la vulnerabilidad excesiva a las recesiones económicas.
} 
ilustrativos para el hogar de un trabajador promedio. Consideremos un hogar cuya única fuente de ingresos son los salarios, que percibe el salario medio de la economía y que no puede variar las horas trabajadas. La descomposición de la volatilidad pertinente para este hogar puede escribirse así:

$$
\sigma_{w}^{2}=\sigma_{\delta}^{2}+\sigma_{\rho}^{2}+2 \operatorname{cov}(\rho, \delta)
$$

donde $\sigma_{w}^{2}$ representa la volatilidad del crecimiento del salario real, $\sigma_{\rho}^{2}$ representa la volatilidad de los salarios reales en relación con el PNB, y los demás términos tienen las interpretaciones obvias. Como antes, la ecuación descompone la volatilidad del salario del trabajador medio en tres componentes: un término macroeconómico, un término idiosincrásico y un término de covarianza.

Cabe formular aquí una advertencia importante: el hecho de basar los cálculos en el salario medio de toda la economía conspira contra la finalidad de la metodología de descomposición, pues empaña la distinción entre el riesgo idiosincrásico y el macroeconómico. Se omite la incidencia de riesgo entre los trabajadores. La única fuente de riesgo idiosincrásico que este cálculo particular puede captar es la que afecta al ingreso laboral medio (sector formal) en relación con otras fuentes de ingreso. Por esa razón, no puede pensarse que el ejercicio ofrece una guía precisa sobre la magnitud relativa de los riesgos idiosincrásicos y macroeconómicos. Es sólo una guía ilustrativa sobre la experiencia de un trabajador "promedio".
El cuadro 5 muestra los cálculos para cuatro países (Chile, México, Perú y Venezuela), seleccionados según la disponibilidad de datos salariales reales, en dos subperíodos posteriores a 1980. El resultado principal que se advierte en este cuadro es la diferencia entre Chile y los demás países de la muestra. Primero, la volatilidad de los salarios reales se incrementó notoriamente en los años noventa en todos los países, salvo en Chile. En este último el crecimiento salarial fue considerablemente más estable en el período posterior al colapso de los años ochenta. Segundo, el crecimiento de los salarios en relación con el ingreso nacional es o bien procíclico (Perú) o pasó a serlo en los años noventa (México y Venezuela), pero no así en Chile. En otras palabras, la volatilidad macroeconómica se transmite a los salarios en estos países de una manera magnificada. Tercero, el componente idiosincrásico de la volatilidad salarial representa para el trabajador promedio alrededor de la mitad o menos de la volatilidad salarial total de los países considerados, salvo Chile. Por lo tanto, las macroperturbaciones y su interacción con los movimientos salariales son una parte importante — si no la más importante— de la incertidumbre salarial en México, Perú y Venezuela. En Chile, es el componente idiosincrásico de los movimientos salariales el que ejerce la influencia dominante.

Estos cálculos y conclusiones son necesariamente provisionales, sobre todo porque uno quisiera efectuar las descomposiciones con datos a nivel del hogar en vez de usar los salarios medios. No obstante, son indicadores del papel importante y creciente que des-

América Latina (cuatro países): Descomposición de la volatilidad del salario reala

\begin{tabular}{|c|c|c|c|c|c|c|c|c|c|}
\hline & \multirow[b]{2}{*}{ Períodos } & \multicolumn{2}{|c|}{$\operatorname{Var}(d \ln w)$} & \multicolumn{2}{|c|}{$\operatorname{Var}(d \ln y)$} & \multicolumn{2}{|c|}{$\operatorname{Var}(d \ln w-d \ln y)$} & \multicolumn{2}{|c|}{$2 x \operatorname{cov}(d \ln y, d \ln w-d \ln y)$} \\
\hline & & Valor & Porcentaje & Valor & Porcentaje & Valor & Porcentaje & Valor & Porcentaje \\
\hline \multirow[t]{2}{*}{ Chile } & 1981-1986 & 2.13 & 100 & 0.77 & 36 & 3.13 & 147 & -1.77 & -83 \\
\hline & 1987-1992 & 0.22 & 100 & 0.13 & 60 & 0.29 & 131 & -0.20 & -91 \\
\hline \multirow{2}{*}{ México } & 1984-1989 & 0.40 & 100 & 0.66 & 165 & 0.21 & 54 & -0.48 & -119 \\
\hline & 1990-1995 & 0.86 & 100 & 0.35 & 41 & 0.42 & 48 & 0.09 & 11 \\
\hline \multirow[t]{2}{*}{ Perú } & 1983-1988 & 3.11 & 100 & 1.30 & 42 & 1.12 & 36 & 0.70 & 23 \\
\hline & 1989-1994 & 6.90 & 100 & 1.61 & 23 & 3.25 & 47 & 2.04 & 30 \\
\hline \multirow[t]{2}{*}{ Venezuela } & 1983-1988 & 0.36 & 100 & 0.34 & 93 & 1.16 & 320 & -1.13 & -312 \\
\hline & 1989-1994 & 1.77 & 100 & 0.53 & 30 & 0.91 & 51 & 0.33 & 19 \\
\hline
\end{tabular}

Fuente: Calculado con datos del Banco Mundial (1999), del FMI (varios años) y del BID ( s/f).

a Las varianzas y covarianzas se han multiplicado por 100. 
empeña la inestabilidad macroeconómica —además de las perturbaciones idiosincrásicas- en impulsar la incertidumbre respecto del ingreso en los trabajadores de la región. Esto implicaría que una mayor estabilidad del entorno macroeconómico debería hacer una contribución sustancial —quizá en algunos casos más que los propios programas de seguro social— a la seguridad económica de los trabajadores.

América Latina y el Caribe es en efecto una región con un nivel muy elevado de volatilidad macroeconómica agregada. Aunque la volatilidad ha disminuido un tanto desde los años de la crisis de la deuda, todavía permanece alta en términos comparativos. El cuadro 6 muestra las cifras de volatilidad para los países de la región correspondientes a los años ochenta y noventa. En términos no ponderados, la volatilidad del crecimiento medio del PNB se ha reducido de 4.5 puntos porcentuales durante los años ochenta a 3.2 puntos en los años noventa. Aun así, es todavía el doble de la que experimenta una economía industrial como la de los Estados Unidos. Además, en varios casos importantes, la volatilidad ha aumentado: en Argentina y Venezuela, países con niveles de volatilidad superiores al promedio, los años noventa han sido, incluso, más volátiles que los ochenta.

El cuadro 7 muestra una comparación a más largo plazo con los años sesenta y setenta para los países más grandes de la región. En vez de presentar desviaciones estándares brutas, he preferido entregar las cifras en forma algo diferente. Las de este cuadro responden a la siguiente pregunta: ¿cuál es la probabilidad en un año dado de que el ingreso per cápita baje $5 \%$ o más? Puesto que la inseguridad económica suele basarse en el temor a una caída abrupta del ingreso, ésta parecería ser una medida mejor que la propia volatilidad. He basado mis cálculos en los promedios

CUADRO 6

América Latina y el Caribe (26 países): Indicadores de la volatilidada

\begin{tabular}{|c|c|c|c|c|c|c|}
\hline \multirow[b]{2}{*}{ País } & \multicolumn{2}{|c|}{ Volatilidad del PNB } & \multicolumn{2}{|c|}{$\begin{array}{l}\text { Volatilidad de la relación } \\
\text { de intercambio del ingreso }\end{array}$} & \multicolumn{2}{|c|}{$\begin{array}{l}\text { Volatilidad de los } \\
\text { flujos de capital privado }\end{array}$} \\
\hline & Años 80 & Años 90 & Años 80 & Años 90 & Años 80 & Años 90 \\
\hline Argentina & 0.048 & 0.050 & 0.007 & 0.004 & 0.032 & 0.058 \\
\hline Bahamas & 0.028 & 0.023 & & & & \\
\hline Barbados & 0.052 & 0.030 & & & 0.047 & 0.045 \\
\hline Belice & 0.032 & 0.010 & & & 0.031 & 0.011 \\
\hline Bolivia & 0.045 & 0.031 & 0.009 & 0.016 & 0.025 & 0.003 \\
\hline Brasil & 0.044 & 0.039 & 0.008 & 0.003 & 0.009 & 0.040 \\
\hline Chile & 0.070 & 0.027 & 0.021 & 0.029 & 0.049 & 0.018 \\
\hline Colombia & 0.015 & 0.016 & 0.019 & 0.011 & 0.010 & 0.012 \\
\hline Costa Rica & 0.045 & 0.024 & 0.042 & 0.014 & 0.068 & 0.028 \\
\hline República Dominicana & 0.047 & 0.043 & 0.030 & 0.035 & 0.023 & 0.036 \\
\hline Ecuador & 0.044 & 0.012 & 0.030 & 0.027 & 0.035 & 0.009 \\
\hline El Salvador & 0.027 & 0.007 & 0.039 & 0.022 & 0.026 & 0.009 \\
\hline Guatemala & 0.049 & 0.052 & 0.013 & 0.013 & 0.011 & 0.006 \\
\hline Guyana & 0.026 & 0.024 & 0.063 & 0.197 & 0.058 & 0.051 \\
\hline Haití & 0.017 & 0.069 & 0.026 & 0.016 & 0.004 & 0.014 \\
\hline Honduras & 0.036 & 0.024 & 0.026 & 0.040 & 0.010 & 0.014 \\
\hline Jamaica & 0.042 & 0.038 & & & 0.039 & 0.024 \\
\hline México & 0.051 & 0.023 & 0.016 & 0.008 & 0.029 & 0.017 \\
\hline Nicaragua & 0.069 & 0.026 & 0.032 & 0.060 & & \\
\hline Panamá & 0.083 & 0.053 & 0.021 & 0.019 & & \\
\hline Paraguay & 0.035 & 0.015 & 0.020 & 0.011 & 0.021 & 0.016 \\
\hline Perú & 0.047 & 0.019 & 0.014 & 0.006 & 0.017 & 0.032 \\
\hline Suriname & 0.060 & 0.074 & & & 0.140 & 0.034 \\
\hline Trinidad y Tabago & 0.043 & 0.022 & & & 0.037 & 0.032 \\
\hline Uruguay & 0.055 & 0.028 & 0.026 & 0.008 & 0.037 & 0.033 \\
\hline Venezuela & 0.050 & 0.052 & 0.060 & 0.030 & 0.085 & 0.104 \\
\hline Media & 0.045 & 0.032 & 0.026 & 0.028 & 0.037 & 0.028 \\
\hline Mediana & 0.045 & 0.027 & 0.023 & 0.016 & 0.031 & 0.024 \\
\hline
\end{tabular}

a La volatilidad se calcula como la desviación estándar de las tasas de crecimiento anual del PNB y la relación de intercambio del ingreso, y la desviación estándar de los flujos brutos de capital privado como proporción del PNB. La información sobre el PNB y la relación de intercambio proviene de la base de datos del BID, y aquella sobre los flujos de capital privado proviene de Banco Mundial (1999). 
CUADRO 7

América Latina (ocho países):

La inseguridad económica en una perspectiva de largo plazo

(Probabilidad de que el ingreso per cápita

caiga $5 \%$ en un año, en porcentaje)

\begin{tabular}{lcccr}
\hline & Años 60 & Años 70 & Años 80 & Años 90 \\
\hline Argentina & 7.9 & 5.4 & 36.5 & 3.3 \\
Brasil & 2.3 & 0.2 & 12.4 & 14.4 \\
Chile & 0.4 & 25.5 & 17.5 & 0.0 \\
Colombia & 0.0 & 0.0 & 0.5 & 0.0 \\
México & 0.0 & 0.0 & 17.1 & 19.0 \\
Perú & 3.5 & 3.6 & 36.5 & 17.8 \\
Uruguay & 4.3 & 0.3 & 28.7 & 0.4 \\
Venezuela & 5.4 & 1.5 & 37.3 & 9.0 \\
& & & & \\
Media & 3.0 & 4.6 & 23.3 & 8.0 \\
Mediana & 2.9 & 0.9 & 23.1 & 6.1 \\
\hline
\end{tabular}

Fuente: Cálculos del autor, basados en los promedios decenales de las tasas de crecimiento del ingreso per cápita y su desviación estándar y suponiendo que las tasas de crecimiento se distribuyen en forma idéntica y normal en una década.

decenales de las tasas de crecimiento y sus desviaciones estándares, suponiendo que las tasas de crecimiento anual se distribuyen en forma idéntica y normal. Para una tasa de crecimiento dada, la probabilidad de una declinación del ingreso de 5\% aumenta con la volatilidad. Por otra parte, para un nivel dado de volatilidad (expresado como la desviación estándar del crecimiento), la misma probabilidad es declinante en la tasa de crecimiento medio. Por ende, las probabilidades señaladas en el cuadro 7 combinan la información tanto de la tasa de crecimiento del ingreso como de su volatilidad.

El cuadro revela que los años noventa registran una enorme mejoría con respecto a los ochenta. Pero también deja en claro que para la mayoría de los países indicados, la inseguridad del ingreso agregado es sustancialmente mayor en los años noventa de lo que era en los años sesenta y setenta. En Brasil, México, Perú y Venezuela, la probabilidad de que los ingresos medios bajen $5 \%$ o más fluctúa en el rango de $10 \%$ a $20 \%$, muy por encima de los niveles anteriores a los años ochenta. Puede decirse que sólo Argentina y Chile han exhibido mejorías claras en la seguridad del ingreso conforme a esta medición. Tomando la muestra de países en su conjunto, la probabilidad media de una contracción abrupta del ingreso (de 5\% o más) en los años noventa es alrededor del doble de la observada en los años sesenta y setenta $(8.0 \%$ contra $3.0 \%$ y $4.6 \%$, respectivamente).

\section{Las fuentes de la volatilidad macroeconómica: la importancia de los flujos de capital}

Las causas de la volatilidad macroeconómica en América Latina han sido investigadas por Hausmann y Gavin (1996). Como lo destacan estos autores, la volatilidad es impulsada tanto por perturbaciones externas como por fallas de política internas. En el frente externo, la inestabilidad de la relación de intercambio y de los flujos de capital son los factores claves (véase algunos datos sobre ellos en el cuadro 6). En lo que toca a las políticas, el colapso de los regímenes de cambio fijo y las políticas monetarias erráticas han desempeñado generalmente un gran papel. Por ende, en general han pesado tanto las perturbaciones exógenas como las instituciones y políticas internas.

Para los años noventa, los datos sugieren que la inestabilidad de los flujos de capital privado ha sido quizá el factor principal de la volatilidad macro- económica. Este es el mensaje central que surge de las regresiones del cuadro 8 .

Dicho cuadro muestra los resultados de regresar promedios de la volatilidad del crecimiento del PNB, tanto para los años ochenta como para los noventa, respecto a varios elementos determinantes: la volatilidad de la relación de intercambio, la volatilidad de los flujos brutos de capital privado, la volatilidad de las condiciones monetarias, la profundización financiera, el ingreso per cápita y una variable ficticia para los años noventa. ${ }^{8}$ La primera columna del cuadro, que agrupa los promedios de ambas décadas (y contiene hasta dos

\footnotetext{
8 Véase un análisis transnacional de índole similar en Easterly, Islam y Stiglitz (1999).
} 


\begin{tabular}{|c|c|c|c|c|}
\hline & \multicolumn{4}{|c|}{ Variable dependiente: desviación estándar de las tasas de crecimiento del PNB } \\
\hline & (1) & $(2)$ & (3) & (4) \\
\hline Constante & $\begin{array}{c}0.087^{*} \\
(0.029)\end{array}$ & $\begin{array}{c}0.067^{*} \\
(0.019)\end{array}$ & $\begin{array}{c}0.044 \\
(0.031)\end{array}$ & $\begin{array}{c}0.079^{*} \\
(0.024)\end{array}$ \\
\hline Log. ingreso per cápita & $\begin{array}{l}-0.009 * * \\
(0.004)\end{array}$ & $\begin{array}{l}-0.006^{* *} \\
(0.003)\end{array}$ & $\begin{array}{l}-0.003 \\
(0.005)\end{array}$ & $\begin{array}{l}-0.009 * * \\
(0.003)\end{array}$ \\
\hline $\begin{array}{l}\text { Volatilidad de la política } \\
\text { monetaria (desv. est. del } \\
\text { crecimiento de M1) }\end{array}$ & $\begin{array}{l}0.011 * * * \\
(0.006)\end{array}$ & $\begin{array}{l}0.010^{* * * *} \\
(0.005)\end{array}$ & $\begin{array}{c}0.012 \\
(0.007)\end{array}$ & $\begin{array}{c}0.003 \\
(0.009)\end{array}$ \\
\hline $\begin{array}{l}\text { Volatilidad de la relación } \\
\text { de intercambio del ingreso }\end{array}$ & $\begin{array}{c}-0.049 \\
(0.112)\end{array}$ & & & \\
\hline $\begin{array}{l}\text { Volatilidad de los flujos } \\
\text { brutos de capital privado }\end{array}$ & $\begin{array}{r}0.505^{*} \\
(0.130)\end{array}$ & $\begin{array}{c}0.454^{*} \\
(0.099)\end{array}$ & $\begin{array}{l}0.419^{* *} \\
(0.177)\end{array}$ & $\begin{array}{c}0.509^{*} \\
(0.127)\end{array}$ \\
\hline $\begin{array}{l}\text { Profundidad financiera } \\
\text { (M2/PNB) }\end{array}$ & $\begin{array}{c}0.0000 \\
(0.0003)\end{array}$ & & & \\
\hline $\begin{array}{l}\text { Variable ficticia para los } \\
\text { años noventa }\end{array}$ & $\begin{array}{l}-0.010 * * \\
(0.005)\end{array}$ & $\begin{array}{l}-0.010^{* *} \\
(0.004)\end{array}$ & & \\
\hline Período cubierto & $\begin{array}{l}\text { Años } 80 \\
\text { Años } 90\end{array}$ & $\begin{array}{l}\text { Años } 80 \\
\text { Años } 90\end{array}$ & Sólo años 80 & Sólo años 90 \\
\hline $\begin{array}{l}\mathrm{N} \\
\mathrm{R}^{2} \text { ajustado }\end{array}$ & $\begin{array}{c}36 \\
0.39\end{array}$ & $\begin{array}{c}44 \\
0.41\end{array}$ & $\begin{array}{c}22 \\
0.16\end{array}$ & $\begin{array}{c}22 \\
0.46\end{array}$ \\
\hline
\end{tabular}

a Las regresiones usan hasta dos observaciones por país, una para los años ochenta y otra para los noventa. Los errores estándar están entre paréntesis. Los asteriscos indican los niveles de significancia:* 99\%; ** 95\%; *** 90\%. Se excluyen de las muestras utilizadas en estas regresiones cuatro países pequeños que registran flujos de capital privado muy volátiles: Suriname, Panamá, Bahamas y Nicaragua.

observaciones por país), indica que la volatilidad de los flujos de capital es un correlato altamente significativo de la volatilidad del PNB. El coeficiente estimado de la volatilidad de la relación de intercambio es insignificante. La profundización financiera (sustituida por M2/PNB) parece no importar. La volatilidad de las condiciones monetarias internas es estadísticamente significativa, pero sólo a un nivel de confianza de $90 \%$. La variable ficticia correspondiente a los años noventa es negativa y significativa, con un coeficiente estimado que es aproximadamente igual a la declinación de la volatilidad media del PNB entre las dos décadas. Por último, hay una asociación negativa y significativa entre ingreso per cápita y volatilidad. La segunda columna del cuadro 8 omite las variables insignificantes (la volatilidad de la relación de intercambio y la profundización financiera) para obtener algunas observaciones adicionales. Los resultados permanecen invariables. En particular, la volatilidad de los flujos bru- tos de capital privado participa con un coeficiente muy significativo.

Las dos últimas columnas del cuadro 8 muestran los resultados cuando las regresiones se ejecutan década por década. Observamos que la asociación entre la volatilidad del PNB y la volatilidad de los flujos de capital privado es particularmente estrecha en los años noventa. De hecho, junto con el ingreso per cápita, la volatilidad de los flujos de capital explica aproximadamente la mitad de la variación internacional de la volatilidad del PNB en América Latina durante los años noventa (comparada con menos de $20 \%$ durante los años ochenta). La estimación del coeficiente indica que un punto de aumento de la desviación estándar de los flujos brutos de capital privado (expresados como porcentaje del PNB) se asoció con un incremento de la desviación estándar de las tasas de crecimiento del PNB de más de medio punto porcentual. La relación excepcionalmente estrecha durante los años noventa entre la 
volatilidad de los flujos de capital y la volatilidad del PNB en la región figura también en el gráfico 2. Como se indica en dicho gráfico, algunos de los países más pequeños de la región con poco acceso a los flujos de capital privado (Bolivia y Guatemala) han tenido los niveles más bajos de volatilidad macroeconómica. Argentina y Venezuela están en el extremo opuesto, con riesgo muy elevado de volatilidad en los flujos de capital privado y, por consiguiente, con altos niveles de macrovolatilidad. Países como Brasil, Chile y Colombia, que han regulado flujos de capital privado, figuran en una situación más bien intermedia.

Es posible interpretar estos resultados de una manera diferente, poniendo de relieve la causalidad en la dirección opuesta. Tal vez los flujos de capital respondan sencillamente a la volatilidad subyacente en el entorno económico y no sean un factor determinante de ella. Esta sería la interpretación apropiada conforme a las premisas de que los flujos de capital privado siguen a las variables macroeconómicas fundamentales y que no hay equilibrios múltiples, de modo que los flujos de capital no constituyen una fuente de perturbaciones independiente. Sin embargo, incluso en este escenario nuestros resultados indican que los flujos de capital, por ser muy sensibles a otras perturbaciones, podrían magnificarlas. En este sentido, los países que están muy

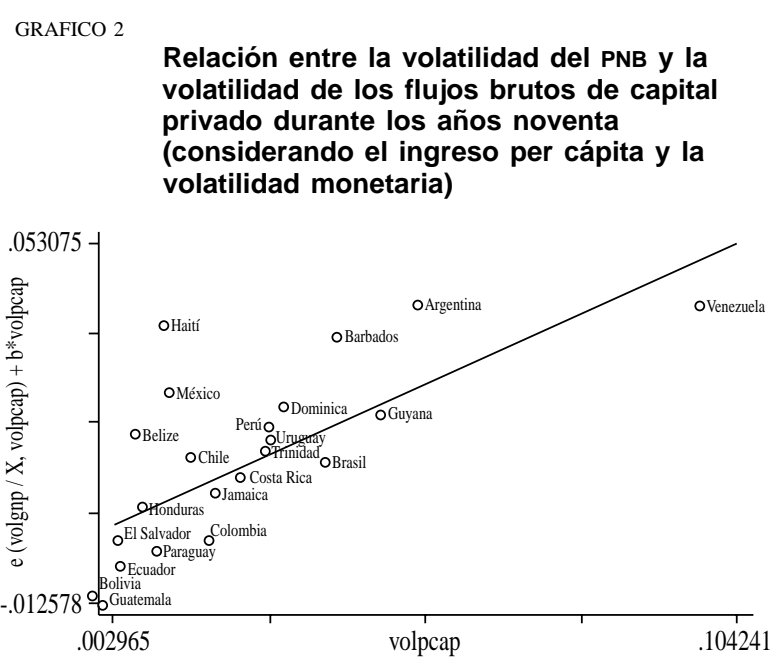

abiertos a las corrientes de capital privado pueden sufrir una volatilidad adicional generada por reversiones de esas corrientes, aunque los flujos de capital respondan sólo a las variables macroeconómicas fundamentales. Este aspecto se retoma con mayor detalle en la sección siguiente, que muestra cómo la movilidad del capital agrava el riesgo para la economía nacional, incluso en casos en que el capital responde sólo a perturbaciones exógenas de la productividad.

\section{VI}

\section{La movilidad del capital y la incidencia del riesgo macroeconómico}

La observación de que los flujos de capital erráticos son un correlato estrecho de la volatilidad macroeconómica tiene una connotación importante para la distribución del riesgo macroeconómico entre los hogares del país. Tal como destacaba la descomposición en una sección previa, los hogares cuyo ingreso relativo covaría con el promedio nacional corren un mayor riesgo en materia de ingreso que aquéllos cuyos ingresos relativos son anticíclicos. En particular, como se destacó en mi ilustración empírica, los trabajadores cuyos salarios reales son procíclicos — aumentan más que el ingreso nacional en épocas propicias, y bajan más que éste en épocas adversas- sufren desproporcionadamente con la volatilidad macroeconómica.

Una consecuencia de la movilidad del capital es precisamente que una mayor proporción del riesgo macroeconómico se traslada a los factores de producción nacionales - como el trabajo- que no son móviles en el plano internacional. Dado que el capital puede entrar y salir en respuesta, por ejemplo, a los cambios bruscos de la productividad interna, puede evadir el riesgo que plantea el carácter estocástico del entorno económico nacional. Pero los flujos de capital imponen con ello una externalidad a los grupos inmóviles en el plano internacional, porque estos últimos tienen ahora que asumir una mayor proporción del riesgo que no es posible diversificar en el país.

Un modelo sencillo, adaptado de Rodrik (1997, cap. 4) ilustra como opera esto. Supongamos una economía pequeña abierta que produce (y exporta) un solo bien, cuyo precio es determinado en los mercados mundiales. Este bien es producido bajo rendimientos 
de escala constantes y utilizando trabajo y capital. A diferencia del trabajo, el capital puede cruzar las fronteras, pero a un cierto costo. La magnitud de este costo será el parámetro que capte el grado de movilidad del capital en la economía. El trabajo, cuyo bienestar es el centro del análisis, sólo consume lo importable. La única fuente de incertidumbre del modelo es el nivel de productividad en el sector exportable, que se supone es estocástico. El ingreso del trabajo se compone del ingreso salarial más lo proveniente de un impuesto al capital nacional.

Sea la función de producción del sector exportable $p f(k, l)$, con las condiciones habituales de regularidad: $f_{k}>0, f_{l}>0, f_{k k}<0, f_{l l}<0$, y $f_{k l}>0$. El parámetro de productividad estocástica está dado por $p$. (De igual forma podríamos pensar que $p$ es la relación de intercambio). Normalizamos la dotación fija de trabajo de la economía a la unidad, de modo que la función de producción pueda expresarse también como $p f(k)$. El acervo de capital de propiedad nacional se fija exógenamente en $k_{0}$. Nótese que $k$, el capital utilizado en el país, puede diferir de $k_{0}$ ya que el capital entra y sale del país. Un supuesto clave es que los capitalistas incurren en un costo creciente cuando el capital cruza las fronteras. Podemos pensar que esto equivale al costo de instalar un negocio en un entorno menos familiar, de transportar de vuelta los bienes finales a la economía matriz, de comunicarse con las filiales en un país diferente, etcétera. La mayor movilidad del capital se captará en el modelo por reducciones del parámetro $\lambda$.

El modelo puede describirse en tres ecuaciones:

$$
\begin{gathered}
r=p f_{k}(k)-\tau \\
r=r^{*}-\lambda\left(k_{0}-k\right) \\
w=p f_{t}(k)
\end{gathered}
$$

La rentabilidad interna del capital ( $r$ ) está dada por el valor marginal del producto del capital una vez deducido el impuesto interno. El comercio internacional de servicios de capital exige que esta rentabilidad sea igual a la internacional $\left(r^{*}\right)$ menos un margen que está relacionado con el costo de trasladar el capital al exterior. Por lo tanto, una salida de capital que redujera el acervo de capital en el país a $k_{l}$ deprimiría la rentabilidad que perciben los capitalistas nacionales a $r^{*}-\lambda\left(k_{0}-k_{l}\right)$. La ecuación [2] expresa esta condición de arbitraje. Por último, la ecuación [3] establece que el salario interno (w) es igual al valor marginal del producto del trabajo. Estas tres ecuaciones determinan las tres variables endógenas del sistema, $w, r, \mathrm{y} k$.
El gráfico 3 ilustra cómo funciona el modelo. La curva de pendiente descendente muestra la relación negativa entre $r$ y $k$ expresada en la ecuación [1]. Al desplazarse la productividad interna $(p)$, también lo hace esta curva. Intuitivamente, para todo monto dado de capital invertido en el país, el rendimiento del capital fluctúa a la par de la productividad en el sector exportable. A su vez, la curva de pendiente ascendente representa la relación expresada en la ecuación [2]. Se muestran dos versiones de esta curva, una para $\lambda$ elevada (escasa movilidad del capital) y otra para $\lambda$ baja (gran movilidad del capital). Mientras más baja es $\lambda$, más plana es esta curva. En el límite, con un capital totalmente móvil a costo nulo, la curva sería horizontal y fijaría la tasa interna de rentabilidad en $r^{*}$.

Denótese por $k(p, \tau, \lambda)$ el nivel de equilibrio del capital empleado en el país. Considérese un equilibrio inicial donde la combinación de parámetros es tal que $k(p, \tau, \lambda)=k_{0}$. En este equilibrio, representado por A en el gráfico $3, r=r^{*}$. Las variaciones de $\lambda$ no tendrían efecto sobre $w$ o $k$ (o $r$ ) a partir de este equilibrio inicial, puesto que

$$
\begin{gathered}
\frac{d k}{d \lambda}=\frac{k-k_{0}}{p f_{k k}-\lambda}, \\
\frac{d w}{d \lambda}=p f_{k l}\left[\frac{k-k_{0}}{p f_{k k}-\lambda}\right]
\end{gathered}
$$

y ambas expresiones son iguales a cero cuando $k=k_{0}$. Intuitivamente, fijamos el equilibrio inicial de manera que el capital no tenga ningún incentivo para entrar o salir de la economía nacional, y por consiguiente las

GRAFICO 3

Funcionamiento del modelo

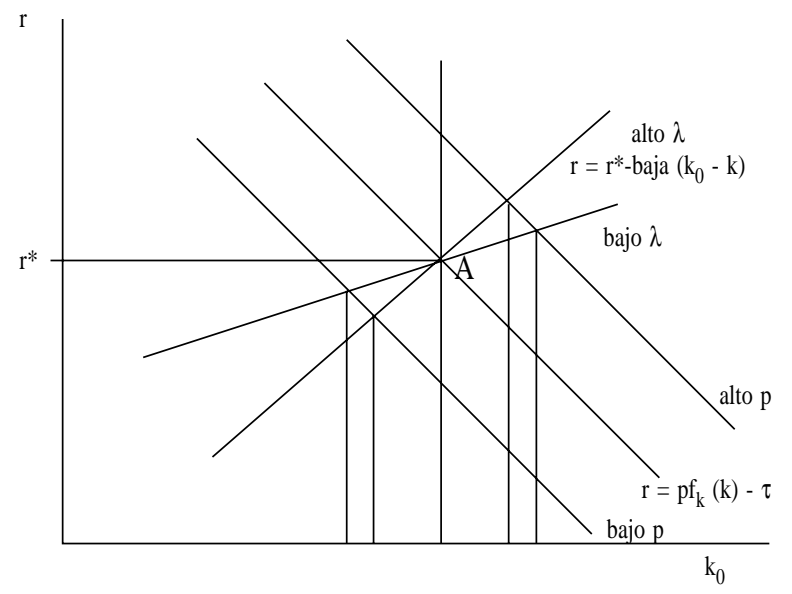


variaciones del costo de la movilidad no tienen importancia (manteniendo $p$ constante).

Considérese ahora qué ocurre si $p$ fluctúa. La reducción de $p$ deprime el rendimiento interno del capital y provoca una salida de capital, cuya magnitud es inversamente proporcional a $\lambda$. Como lo demuestra el gráfico, mientras mayor es la movilidad del capital, más amplias son las fluctuaciones del acervo de capital interno en respuesta a las variaciones del precio mundial. Formalmente,

$$
\frac{d k}{d p}=\frac{f_{k}}{\lambda-p f_{k k}}>0,
$$

que decrece respecto a $\lambda$. Las consecuencias para la fuerza de trabajo pueden deducirse fácilmente. Dado que el salario interno (en términos de lo importable) está determinado por el valor marginal del producto del trabajo en lo exportable —ecuación [3]—, la movilidad del capital acentúa la fluctuación del salario de consumo. Mientras más baja es $\lambda$, mayor es la amplitud de las fluctuaciones en $w$ :

$$
\frac{d w}{d p}=f_{l}+\frac{p f_{k \ell} f_{k}}{\lambda-p f_{k k}}>0,
$$

que es decreciente en $\lambda$.

De hecho, las cosas son incluso peores para el trabajo en la medida en que parte del ingreso de los trabajadores proviene del impuesto al capital. Siendo $I$ el ingreso (real) de los trabajadores,

$$
I=w+\tau k
$$

Por lo tanto, las fluctuaciones de $I$ provienen no sólo de las fluctuaciones salariales, sino también de las fluctuaciones de la base impositiva $(k)$ a medida que el capital va y viene en busca de rendimientos mayores.

Así, al hacer el capital más sensible a los cambios de la productividad interna, la movilidad del capital magnifica la amplitud de las fluctuaciones de los ingresos de los trabajadores en el país. El efecto se produce porque los ingresos de los trabajadores dependen no sólo de la productividad interna, sino también de i) el acervo de capital interno, que fluctúa en respuesta a los cambios bruscos de la productividad, y ii) la base impositiva de la economía, que también fluctúa en mayor medida como resultado de la movilidad del capital. El efecto de tal movilidad es que el trabajo está expuesto a un mayor riesgo macroeconómico. Esto puede considerarse con propiedad como una externalidad negativa que el capital impone al trabajo. Además, cuando la movilidad del capital es suficientemente elevada, se torna imposible compensar el trabajo mediante ajustes adecuados del impuesto al capital: la movilidad del capital permite que los capitalistas evadan el impuesto, lo que deja a los trabajadores en peor situación aún. El modelo capta de manera esquemática un dilema de política que se plantea en todo el mundo, pero con especial fuerza en América Latina, donde la volatilidad de los flujos de capital es particularmente significativa.

\section{VII}

\section{Los tipos de cambio, la movilidad del capital y la volatilidad macroeconómica}

Ya se ha señalado la asociación entre política cambiaria y volatilidad macroeconómica: el colapso de tipos de cambio fijos insostenibles ha sido tradicionalmente una fuente importante de inestabilidad para los países latinoamericanos. Una de las observaciones de Hausmann y Gavin (1996) es que los países con tipos de cambio flexibles han experimentado una menor volatilidad del PNB que los países con tipos de cambio fijos. Una razón es que se evitan las crisis monetarias. La otra es que los tipos de cambio flexibles aíslan mejor que los fijos de las perturbaciones reales: una baja de la productividad en los sectores transables o de la relación de intercambio puede solucionarse con una depreciación monetaria inmediata, soslayando un proceso de ajuste que en un régimen de tipo de cambio fijo tendría que producirse a través de variaciones de los precios internos y tardaría mucho más.

La movilidad del capital en los años noventa ha socavado la capacidad de los tipos de cambio flexibles para cumplir esa función estabilizadora. Cuando no son 
fijos, los tipos de cambio se han guiado menos por las perturbaciones de la competitividad o las fluctuaciones de la balanza comercial y más por el deseo de mantener los flujos de capital a corto plazo y la confianza de los inversionistas. Michael Gavin sintetiza así la respuesta en la región a las perturbaciones ocurridas a partir de la crisis asiática:

El primer hecho estilizado es que pese a la magnitud de las perturbaciones externas, la mayoría de los países usó su flexibilidad cambiaria con mucha parsimonia... En Perú —un país con un tipo de cambio flotante oficial que fue afectado severamente por El Niño y el colapso de la relación de intercambio- la devaluación acumulativa apenas se mantuvo a la par de la inflación. Chile también permitió movimientos mínimos de su tipo de cambio pese a la gran caída del precio del cobre y de la demanda asiática de sus exportaciones (Gavin, 1999, p. 3).

El autor citado pasa a analizar cómo la política que se eligió como respuesta fue la de recurrir en cambio a la tasa de interés, que se utilizó agresivamente para defender el tipo de cambio. En otras palabras, en vez de dejar que el tipo de cambio nominal se depreciara lo suficiente para dar un impulso a la economía real, los gobiernos latinoamericanos optaron por restringir las condiciones monetarias para impedir la depreciación. La política cambiaria se desvinculó de las necesidades de la economía real.

El cuadro 9 ofrece una visión más sistemática de lo anterior al analizar la correlación entre los tipos de cambio reales y los flujos de la balanza de pagos de diferentes clases. El ejercicio está inspirado en uno similar publicado por la oIT (1999, cuadro 3), que sólo abarca un país latinoamericano. En él se calculan los coeficientes de correlación entre los movimientos trimestrales del tipo de cambio real y los flujos de dos clases: flujos "reales" y flujos "financieros". La primera categoría de flujos se define como la suma de la cuenta corriente y la afluencia de inversión extranjera directa (IED). La segunda categoría abarca todos los movimientos de la cuenta de capital salvo la IED y las variaciones de las reservas, e incluye errores y omisiones. ${ }^{9}$ El ejercicio se realiza para todos los principa-

\footnotetext{
${ }^{9}$ Nótese que dado que las variaciones de las reservas están excluidas de los cálculos, los dos conjuntos de correlaciones no tienen que producir resultados simétricos (idénticos en valor absoluto y de signo contrario).
}

CUADRO 9

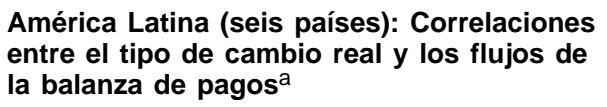

\begin{tabular}{lccc}
\hline & \multicolumn{3}{c}{$\begin{array}{c}\text { Coeficiente de correlación entre el } \\
\text { tipo de cambio real y: }\end{array}$} \\
\cline { 2 - 4 } & $\begin{array}{c}\text { Cuenta corriente } \\
+ \text { IED }\end{array}$ & $\begin{array}{c}\text { Entradas } \\
\text { financieras }\end{array}$ & Período $^{\mathrm{b}}$ \\
\hline Argentina & 0.19 & $-0.52 *$ & 89T2-98T4 \\
Brasil & $0.40^{* * *}$ & -0.23 & 93T1-97T4 \\
Chile & -0.24 & -0.03 & 89T1-98T4 \\
México & $0.68 *$ & $-0.69 *$ & 89T1-98T4 \\
Perú & 0.40 & 0.21 & 94T1-97T4 \\
Venezuela & 0.24 & -0.06 & 94T1-98T4 \\
\hline
\end{tabular}

Fuente: Calculado con datos de FMI (varios años).

a Los tipos de cambio están definidos en términos de moneda nacional por unidad de moneda extranjera, de modo que un incremento es una depreciación real. Las entradas financieras corresponden a todos los movimientos de la cuenta de capital distintos de la afluencia de inversión extranjera directa (IED) y variaciones de reservas, incluidos errores y omisiones. Los períodos se seleccionaron según la disponibilidad de datos trimestrales. Los niveles de significancia estadística son los siguientes: $* 99 \%$; $* * 95 \%$; *** $90 \%$.

b $\mathrm{T}=$ trimestre.

les países latinoamericanos sobre los cuales el FMI ha publicado en las International Financial Statistics datos trimestrales pertinentes por algún tiempo durante los años noventa. Son seis países en total.

Los resultados entregan un relato consistente. $\mathrm{La}$ correlación entre los flujos financieros y los movimientos del tipo de cambio real es negativa en todos los casos, salvo en Perú. Esto indica que hay una tendencia general a que el tipo de cambio real se aprecie en respuesta a la afluencia financiera. La correlación entre el tipo de cambio real y los flujos reales, por otra parte, es positiva en cinco de los seis casos (aquí Chile es la excepción). En otras palabras, en todos los países, salvo Chile, el deterioro de la cuenta corriente (y del balance de la IED) está vinculado con una apreciación del tipo de cambio real.

Lo que estos resultados parecen reflejar es un patrón cada vez más habitual en que los flujos financieros llevan las riendas del tipo de cambio real. En lo que respecta a la demanda estabilizadora de la producción interna, el tipo de cambio tiende a moverse en la dirección "correcta" en el caso de los flujos financieros - una reducción de las entradas deprecia el tipo de cambio real-, pero al moverse en la dirección "errada" en el caso de los flujos comerciales, un deterioro de la cuenta corriente se acompaña de una apreciación del tipo de cambio real. Este patrón es clarísimo en el 
caso de México, donde la entrada creciente de recursos financieros y el deterioro de la cuenta corriente entre 1988 y 1994 fueron equiparados con una apreciación real continua de la moneda. Esto se registra en el cuadro 9 en la forma de correlaciones muy estrechas entre estos flujos y el tipo de cambio real. Naturalmente, es posible interpretar la experiencia de México como una apreciación de equilibrio de la moneda en previsión de futuros aumentos de la productividad, pese a la eventual crisis del peso; no obstante, ocurre que el tipo de cambio real estuvo regido por las expectativas de los inversionistas de corto plazo y no por el estado de la demanda interna o el enorme y creciente déficit en cuenta corriente.

\section{VIII}

\section{La flexibilidad cambiaria como seguro social}

El manejo de la política cambiaria durante los años noventa ha contribuido también a una mayor inseguridad económica en la región de manera más sutil. Un tipo de cambio que está dirigido a la economía real no sólo desempeña una función estabilizadora; sirve también como un seguro. La razón es que cuando el tipo de cambio sigue el comportamiento de la cuenta corriente, las perturbaciones de la competitividad de las industrias se disipan a través de toda la economía mediante variaciones del valor de la moneda. Por otra parte, cuando el tipo de cambio es fijo o es sensible sobre todo a los flujos financieros, las industrias afectadas tienen que soportar todo el peso de la perturbación. Dado que éste es un aspecto que en general no se reconoce, lo explicaré con un modelo sencillo.

Considérese una economía abierta pequeña que produce dos bienes transables ( 1 y 2) y un solo bien no transable ( $n$ ). Supóngase, para simplificar, que ninguno de los dos bienes transables se consume en el país, y que la producción interna total de ellos se exporta. Los hogares consumen el bien no transable así como un bien importado que no se produce en el país. Fijemos los precios mundiales (exógenos) de los bienes transables en la unidad. Sea $e$ el tipo de cambio nominal en unidades de la moneda del país por moneda extranjera. El precio interno de los tres bienes transables (los dos exportables y el importable) está dado entonces por $e$. Sea $p$ el precio del bien no transable.

Simplifiquemos más la estructura de la economía suponiendo que el trabajo es el único factor de producción, y que cada uno de los tres sectores productivos del país utiliza mano de obra específica para esa actividad en particular. No hay movilidad intersectorial de la mano de obra. Digamos que la mano de obra de cada tipo suministrada en forma inelástica esté dada por $\bar{l}_{1}, \bar{l}_{2}$ y $\bar{l}_{n}$, con sus correspondientes salarios $w_{1}, w_{2} \mathrm{y}$ $w_{n}$, y que la productividad laboral en los tres sectores esté dada por $a_{1}, a_{2}$ y 1 , respectivamente.

Para permitir que la política cambiaria nominal tenga efectos reales, supondremos que $w_{1} \mathrm{y} w_{2}$ son rígidos a la baja. Esto implica que cuando los costos unitarios de la mano de obra sobrepasan los precios en cualquiera de los sectores exportadores, la mano de obra de ese sector quedará desempleada. Formalmente,

$$
l_{1}=\left\{\begin{array}{c}
\bar{l}_{1} \text { if } w_{1} \leq e a_{1}, \\
0 \text { en los demás casos }
\end{array}\right.
$$

y de manera similar para el otro sector exportador:

$$
l_{2}=\left\{\begin{array}{c}
\bar{l}_{2} \text { if } w_{2} \leq e a_{2}, \\
0 \text { en los demás casos }
\end{array}\right.
$$

La mano de obra en el sector no transable está siempre con pleno empleo, y la relación precio-costo en ese sector está dada por

$$
w_{n}=p
$$

Nótese que las desigualdades en [2.1] y [2.2] se mantendrán como igualdades mientras la mano de obra del tipo respectivo no esté desempleada.

Para cerrar el modelo, tenemos que especificar la igualdad entre demanda y oferta. Supondremos que la balanza comercial está equilibrada, de modo que para nuestros fines basta con establecer la igualdad entre oferta y demanda para los transables. Supóngase que $Y=e a_{1} l_{1}+e a_{2} l_{2}+p l_{n}$ represente el ingreso agregado, y $D(e, p, Y)$ la función de demanda de los importables. La ecuación de la balanza comercial es:

$$
a_{1} l_{1}+a_{2} l_{2}-D(e, p, Y)=0 .
$$


Convendrá trabajar con una forma funcional específica, de modo que supondremos que las preferencias son Cobb-Douglas. Sea $\alpha$ la que represente la participación presupuestaria de los importables, de manera que $D()=.\alpha Y / e$. Entonces, la ecuación de la balanza comercial puede escribirse así:

$$
(1-\alpha) a_{1} l_{1}+(1-\alpha) a_{2} l_{2}-\alpha\left(\frac{p}{e}\right) \bar{l}_{n}=0 .
$$

Para ver cómo funciona el modelo, considérese primero el caso sin rigidez salarial. Entonces tenemos pleno empleo con $l_{1}=\bar{l}_{1}$ y $l_{2}=\bar{l}_{2}$, y la ecuación [2.4] determina el "tipo de cambio real" $(e / p)$ como una función de las productividades laborales $a_{1}$ y $a_{2}$. Una disminución de la productividad de cualquiera de los sectores exportadores provoca una depreciación del tipo de cambio real (un aumento de $e / p$ ). Las ecuaciones [2.1] a [2.3] nos dan tres ecuaciones adicionales con variables endógenas adicionales $w_{1}, w_{2} \mathrm{y}$ $w_{n}$. Tenemos un total de cuatro ecuaciones y cinco precios (los tres salarios más $p$ y $e$ ), de modo que sólo pueden determinarse cuatro precios relativos. No importa que se utilice como numerario el tipo de cambio nominal o una de las remuneraciones salariales.

Para referencia futura, hagamos el análisis estático comparativo del caso sin rigidez nominal. (Las soluciones de este caso seguirán siendo válidas también en condiciones de rigidez salarial, mientras no se requiera en equilibrio un ajuste a la baja de los salarios del sector transable). Considérese un cambio en $a_{1}$, mientras $a_{2}$ permanece invariable. Defínase, $\theta \equiv \frac{a_{1} \bar{l}_{1}}{a_{1} \bar{l}_{1}+a_{2} \bar{l}_{2}}$, siendo $1>\theta>0$. Entonces puede demostrarse que los precios relativos se mueven como sigue:

$$
\begin{aligned}
& \hat{w}_{1}-\hat{e}=\hat{a}_{1} \\
& \hat{w}_{1}-\hat{p}=(1-\theta) \hat{a}_{1} \\
& \hat{w}_{2}-\hat{e}=0 \\
& \hat{w}_{2}-\hat{p}=-\theta \hat{a}_{1} \\
& \hat{w}_{n}-\hat{e}=\theta \hat{a}_{1} \\
& \hat{w}_{n}-\hat{p}=0,
\end{aligned}
$$

donde una cejilla indica el cambio proporcional $(\hat{x} \equiv d x / x)$. Estas relaciones nos permiten determinar los efectos en los salarios reales y, por ende, el bienestar de cada uno de los tres grupos de trabajadores.
Supóngase que la productividad del sector 1 disminuye $\left(\hat{a}_{1}<0\right)$. De las ecuaciones [2.5] y [2.6] vemos que los trabajadores del sector 1 pierden claramente. Los trabajadores de la otra industria exportadora (sector 2) se benefician, no obstante, puesto que su salario permanece invariable en términos de lo importable pero aumenta en términos del bien no transable (véanse las ecuaciones [2.7] y [2.8]). Los trabajadores del sector no transable pierden, debido a la depreciación real del tipo de cambio. Estos resultados son independientes del "régimen cambiario", puesto que en un modelo sin rigidez salarial, el tipo de cambio nominal no tiene ningún efecto real.

\section{La rigidez del salario nominal y los tipos de cambio fijos}

Considérese ahora qué ocurre cuando postulamos que los salarios de ambos sectores transables sean rígidos a la baja, es decir $\hat{w}_{1} \geq 0$ y $\hat{w}_{2} \geq 0$. El tipo de cambio ahora sí importa porque en un régimen de cambio fijo (con $\hat{e}=0$ ), el ajuste a la baja de los salarios en relación con los precios de los bienes transados queda bloqueado. Puesto que se precisa un ajuste de esta especie para mantener el pleno empleo cuando una empresa se ve afectada por una perturbación negativa de su productividad, el resultado será desempleo.

El análisis comparativo estático de este caso, con $\hat{a}_{1}<0$ como antes, da los siguientes resultados en regímenes de cambio fijo.

$$
\begin{gathered}
d l_{1}=-\bar{l}_{1} \\
\hat{w}_{2}-\hat{e}=0 \\
\hat{w}_{2}-\hat{p}=-\theta \hat{a}_{1}+\theta \\
\hat{w}_{n}-\hat{e}=\theta \hat{a}_{1}-\theta \\
\hat{w}_{n}-\hat{p}=0 .
\end{gathered}
$$

Observamos tres cambios. Primero, todos los trabajadores de la industria 1 pierden sus empleos [ecuación 2.11]. Segundo, los trabajadores de la industria 2 experimentan ahora un aumento incluso mayor de sus salarios reales (compárense [2.8] y [2.8'], recordando que $\hat{a}_{1}<0$ ). Tercero, los trabajadores del sector no transable experimentan una caída mayor de su salario real (compárense [2.9] y [2.9']). Los dos últimos resultados se deben a una variación más abrupta del tipo de cambio real cuando la rigidez salarial combinada 
con tipos de cambio fijo conduce al desempleo. Se intuye lo siguiente: cuando la industria exportadora 1 colapsa como resultado de haberse tornado no competitiva, el déficit comercial incipiente es mucho mayor, y la corrección requerida de los precios relativos es también mucho mayor.

El resultado que importa desde nuestra perspectiva es que se acentúan los efectos distributivos de la perturbación de la productividad. La rigidez salarial combinada con tipos de cambio fijo provoca no sólo resultados ineficientes (captados aquí por el desempleo), sino también una mayor dispersión de los resultados distributivos.

\section{La rigidez del salario nominal y los tipos de cambio flexibles}

Cuando el tipo de cambio no es fijo, y se puede focalizar en la balanza comercial, estos efectos pueden compensarse mediante una depreciación del tipo de cambio nominal de magnitud suficiente para restablecer los costos unitarios de la mano de obra en la industria 1 a su nivel original (es decir, $\hat{e}=-\hat{a}_{1}$ ). La flexibilidad en $e$ permite reducir el salario del sector 1 en función de los precios de los bienes transados, eli- minando el desempleo. Por lo tanto, las ecuaciones [2.5] a [2.10] continúan describiendo el comportamiento de la economía, pese a la rigidez a la baja en $w_{i}$. Los resultados distributivos son los mismos que en ausencia de rigidez salarial.

Los resultados de las perturbaciones de la productividad en el sector 2 son análogos, y no es necesario analizarlos en detalle. El cuadro 10 reseña los impactos distributivos de los tres sectores, con perturbaciones tanto positivas como negativas. Nótese que en las perturbaciones positivas de la productividad, los impactos distributivos no dependen de si el tipo de cambio es fijo $\mathrm{u}$ orientado a la balanza comercial. Esto obedece al supuesto (plausible) de que los salarios son rígidos a la baja pero no al alza.

En consecuencia, los resultados no clásicos rigen con tipos de cambio fijo solamente cuando uno de los sectores sufre una perturbación negativa. Cuando eso ocurre, los efectos distributivos se agravan con tipos de cambio fijos merced a los dos conductos ya mencionados: primero, el ingreso colapsa en el sector afectado debido al desempleo; y segundo, hay una mayor variación del precio relativo que beneficia al otro sector transable en detrimento del sector no transable.

CUADRO 10

Efectos distributivos de las perturbaciones (shocks) de la productividad en diferentes regímenes cambiarios

\begin{tabular}{|c|c|c|c|c|c|c|c|c|c|c|c|c|}
\hline \multirow[b]{3}{*}{$\begin{array}{l}\text { Régimen } \\
\text { cambiario }\end{array}$} & \multicolumn{6}{|c|}{ Perturbación en el sector exportador 1} & \multicolumn{6}{|c|}{ Perturbación en el sector exportador 2} \\
\hline & \multicolumn{3}{|c|}{$\begin{array}{c}\text { Positiva }\left(\hat{a}_{1}>0\right) \\
\text { Implicación para el sector }\end{array}$} & \multicolumn{3}{|c|}{$\begin{array}{c}\text { Negativa }\left(\hat{a}_{1}>0\right) \\
\text { Implicación para el sector }\end{array}$} & \multicolumn{3}{|c|}{$\begin{array}{c}\text { Positiva }\left(\hat{a}_{2}>0\right) \\
\text { Implicación para el sector }\end{array}$} & \multicolumn{3}{|c|}{$\begin{array}{c}\text { Negativa }\left(\hat{a}_{2}>0\right) \\
\text { Implicación para el sector }\end{array}$} \\
\hline & 1 & 2 & $n$ & 1 & 2 & $n$ & 1 & 2 & $n$ & 1 & 2 & $n$ \\
\hline $\begin{array}{l}\text { Tipos de } \\
\text { cambio fijos }\end{array}$ & + & - & + & --- & ++ & -- & - & + & + & ++ & --- & -- \\
\hline $\begin{array}{l}\text { Tipos de } \\
\text { cambio flexibles }\end{array}$ & + & - & + & - & + & - & - & + & + & + & - & - \\
\hline
\end{tabular}

a El modelo supone que los salarios nominales son rígidos a la baja en los sectores 1 y 2 . Véase en el texto la descripción del modelo y el análisis. 


\section{IX}

\section{Instituciones de expresión}

El término de los regímenes militares y la transición a la democracia han sido los acontecimientos más alentadores ocurridos en América Latina en las dos últimas décadas. Los datos de diversos países sugieren que las sociedades con mayor apertura y participación política se ajustan mejor a las perturbaciones externas, experimentan una menor volatilidad económica y generan menos inflación (Rodrik, 1998). Por ende, la institucionalización de la democracia debería producir en definitiva resultados económicos más estables y aliviar la inseguridad económica en la región.

La evidencia transnacional sobre la relación entre el tipo de régimen político y la estabilidad económica figura en los gráficos 4 y 5 . Estos diagramas de dispersión - para un conjunto de 96 países - presentan la asociación (parcial) entre una medida de participación política de las no elites y dos indicadores de volatilidad macroeconómica en el lapso de dos décadas (años setenta y ochenta). Las medidas de la volatilidad son la desviación estándar de las tasas de crecimiento del PNB real (gráfico 4) y la tasa de inflación media (gráfico 5). La medida de la participación (parcomp) es un índice tomado del conjunto de datos Polity III de Jaggers y Gurr (1995), y se define como la medida en que las no elites son capaces de acceder a las estructuras institucionales de expresión política. Esta última tiene una estrecha correlación con las medidas habituales de democracia (como el índice Freedom House que se utiliza habitualmente), pero he observado que es un mejor predictor de la volatilidad macroeconómica. Las regresiones en que están basados los diagramas de dispersión contienen los siguientes controles adicionales: ingreso per cápita, tamaño de la población, volatilidad de la relación de intercambio y variables ficticias regionales para América Latina, Africa y Asia oriental. Los diagramas de dispersión muestran la asociación entre participación política y volatilidad considerando estas otras variables.

La participación política resulta tener una estrecha correlación negativa tanto con la volatilidad del PNB como con los niveles de inflación. Aunque correlación no prueba causación, otros estudios econométricos y una serie de estudios de caso sugieren que la medida en que un sistema político está abierto a la participación desde abajo sí afecta para mejor la calidad de la

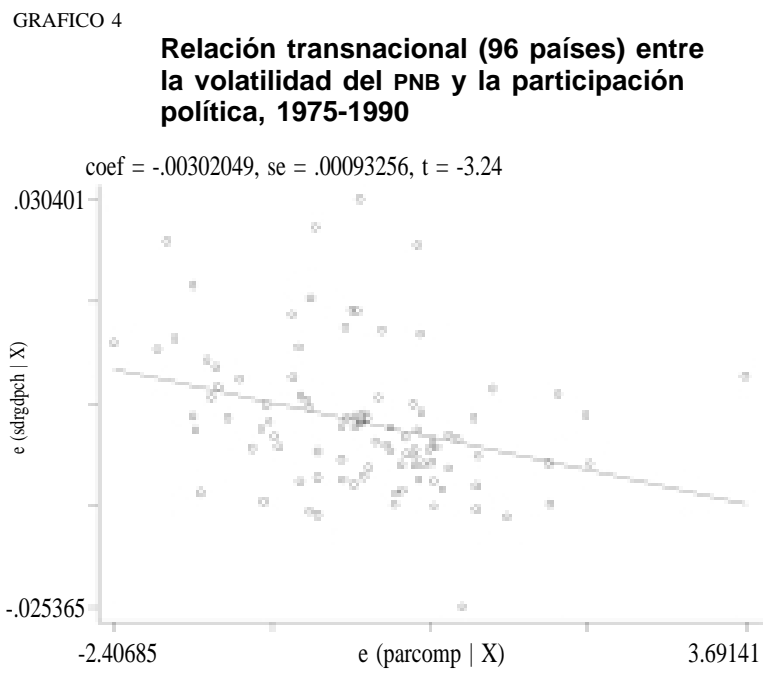

GRAFICO 5

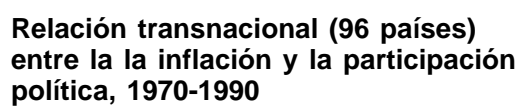
política, 1970-1990

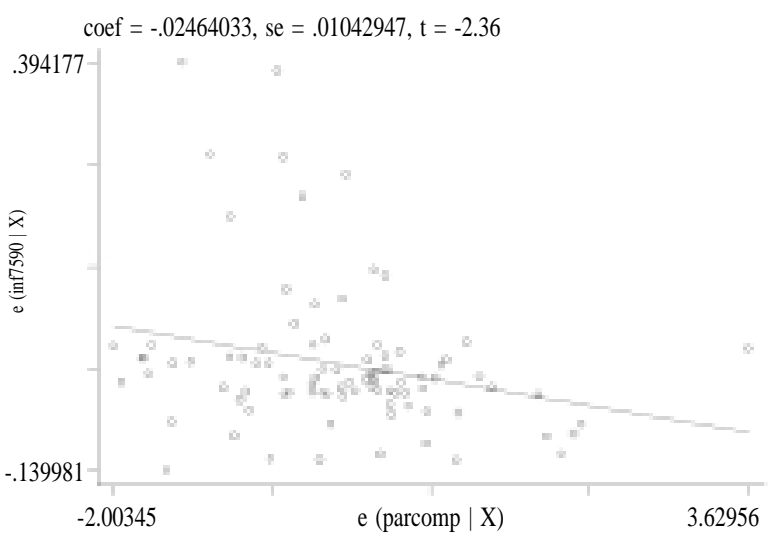

gestión macroeconómica (véase Rodrik, 1999, y publicaciones allí mencionadas). La participación es útil por varios motivos. Primero, la democracia permite transferir el poder sin contratiempos desde políticos (y políticas) fracasados a un nuevo grupo de líderes de gobierno. Segundo, la participación posibilita el establecimiento de mecanismos de consulta y negociación, lo que permite que las autoridades creen el consenso necesario para emprender con decisión los ajustes de política indispensables. Tercero, los mecanismos 
institucionalizados de expresión (voz) obvian la necesidad de los grupos afectados de recurrir a disturbios, protestas y otras acciones perturbadoras, y reducen también el apoyo que otros grupos de la sociedad dan a esa conducta.

Las instituciones de participación en América Latina retienen, sin embargo, varias deficiencias importantes, pese a la transición a la democracia. Estas deficiencias tienen que verse como uno de los elementos que agravan la inseguridad económica: cuando grandes segmentos de la población carecen de un mecanismo eficaz de expresión en asuntos que los afectan, es natural que sientan que controlan menos sus destinos.

Cabe recordar que los sindicatos, una institución importante de expresión colectiva, han perdido afiliados en todos los países con datos al respecto, salvo Chile. Los sindicatos son importantes para los trabajadores no sólo porque obran como grupos de presión en el ámbito político, sino también porque permiten la participación en la toma de decisiones en el lugar de trabajo. Por ambos conceptos, los sindicatos brindan a sus miembros una mayor sensación de que controlan su entorno laboral. Como lo plantea Pencavel (1997, p. 58) en su análisis de América Latina:

Es importante ...que los trabajadores no se sientan alienados del sistema económico y social y [que] perciban que tienen intereses en él. El proceso tiene importancia: aunque los resultados sean idénticos, los empleados valoran el hecho de que ellos o sus agentes contribuyan a configurar su entorno laboral. El sindicato ha sido el vehículo primordial para alcanzar tal situación.

El viejo estilo de actividad sindical en América Latina — cabildear para obtener protecciones laborales y ventajas salariales establecidas por ley- podría decirse que no se adapta bien a las exigencias de economías con mercados competitivos y unidades de producción más pequeñas. Hasta ahora, los sindicatos se han asociado muy a menudo con políticas populistas y proteccionistas. Tal como lo sostienen Márquez y Pages (1998), ni los líderes sindicales ni las autoridades han logrado crear todavía un entorno en que los sindicatos sean considerados suficientemente sensibles a las necesidades de los trabajadores como grupo.

El sistema político latinoamericano, en general, confronta lo que J. Domínguez denomina una "crisis de representación". Según dicho autor, las formas tradicionales de representación - los partidos populistas y los llamados arreglos corporativistas - se han debilitado precisamente en el momento en que hay que buscar el apoyo público que contribuya a garantizar la estabilidad de las reformas económicas y del gobierno constitucional. Los funcionarios de gobierno en América Latina son percibidos como corruptos, los partidos políticos como un conjunto de facciones, los parlamentos como ineficaces y los presidentes o bien como salvadores o bien como granujas que deben ser sometidos a una acusación constitucional. Aunque los golpes militares casi han desaparecido, han surgido nuevas formas de amenaza al constitucionalismo: el gobierno por decreto presidencial, los motines encabezados por militares de rango medio descontentos y golpes presidenciales contra el parlamento, los tribunales y todos los vehículos que sirven para que la sociedad civil procure la defensa y representación de sus intereses (Domínguez, 1997, pp. 109-112). Han estallado motines militares en Argentina, Ecuador, Guatemala, Panamá y Venezuela. Ha habido tentativas de golpe presidencial en Guatemala, Perú y Venezuela.

El coronel Hugo Chávez, paracaidista venezolano, caracteriza todas estas tendencias: en 1992 fracasó en su intento de derrocar el gobierno de Venezuela elegido democráticamente. Aun así, su tentativa fue lo suficientemente popular como para darle una clara mayoría en las elecciones presidenciales de 1998. A fines de 1999, Chávez mantenía altos índices de popularidad pese a su decisión de disolver efectivamente el parlamento y reemplazarlo por una asamblea constituyente elegida para redactar una nueva constitución. Este es un indicio de la frustración manifiesta que sienten los latinoamericanos respecto a sus sistemas políticos.

Como en tantas otras circunstancias, Chile resulta ser la excepción a muchas de estas tendencias. La transición a la democracia en Chile en 1990 se acompañó del inicio de un diálogo social entre trabajadores, empresarios y gobierno, y de una serie de acuerdos anuales tripartitos. El gobierno democráticamente elegido de Patricio Aylwin procuró brindar legitimidad social a sus políticas económicas mediante el incremento del gasto en programas sociales y recurriendo al movimiento laboral. Uno de los primeros logros legislativos importantes del gobierno de Aylwin fue un aumento impositivo destinado a financiar gasto social (Domínguez, 1998). Los acuerdos tripartitos permitieron que los sindicatos participaran en la toma de decisiones del país sobre asuntos tales como el aumento del salario mínimo y la reforma de las leyes laborales. Según Cortázar (1997), las coaliciones de centro izquierda que han gobernado Chile desde 1990 han considerado que los sindicatos son una oportunidad para el desarrollo y no una amenaza a éste. Los empleadores, por 
su parte, han estimado conveniente en el período posterior a Pinochet tener un copartícipe social en la mesa de negociaciones para evitar conflictos sociales. El resultado ha sido un sistema comparativamente armóni- co de relaciones laborales, ${ }^{10} \mathrm{y}$ un sistema político que posee tal vez una medida sorprendente de legitimidad popular, pese a que no ha podido librarse de algunas ataduras heredadas de Pinochet.

\section{X}

\section{Observaciones finales}

He sostenido en este artículo que la inseguridad económica en América Latina es multifacética y tiene muchas fuentes que se nutren unas de otras. Parte de la inseguridad emana de la menor protección del empleo y la mayor volatilidad de los resultados de los hogares. Parte de ella deriva de flujos de capital erráticos y de la inestabilidad sistémica generada por el divorcio entre los instrumentos de estabilización y la economía real. Por último, un componente importante es la debilidad de las instituciones de expresión y representación.

De lo anterior se desprende que los programas destinados a la protección social per se sólo prestan una ayuda parcial. Las redes de seguridad que funcionan bien - compensación por desempleo, prestaciones de vejez y atención médica, fondos sociales focalizadospueden servir para paliar algunos de los riesgos idiosincrásicos que encaran los hogares. Pero tendrán que complementarse con políticas macroeconómicas (en particular relativas a los flujos de capital y el tipo de cambio) que sean más conducentes a la estabilidad de la economía real, y con la relajación del control que ejercen los mercados financieros sobre los instrumentos de la política macroeconómica. Asimismo, tendrán que tener acceso a instituciones representativas — sindicatos, partidos políticos y órganos legislativos-que tengan mayor sensibilidad y legitimidad que las que existen actualmente.

Pero tal vez lo que más necesita América Latina es una visión de cómo se puede mantener la cohesión social frente a grandes desigualdades y a resultados volátiles, agravados ambos por una confianza creciente en las fuerzas del mercado. En los países industrializados de hoy, la expansión del papel de los mercados ha ido tradicionalmente de la mano con el fortalecimiento de las instituciones de seguro social. Desde el Nuevo Trato en los Estados Unidos, y sobre todo desde la Segunda Guerra Mundial en Europa, eso ha significado el crecimiento del sector público y la construcción de un Estado benefactor. Para que América Latina se labre una trayectoria diferente, la región tendrá que desarrollar una visión alternativa que lleve a aliviar la tensión entre las fuerzas del mercado y las ansias de seguridad económica.

Lo bueno es que este asunto está por lo menos encarándose. Lo malo es que hasta ahora nadie, y menos aun los economistas, tiene una respuesta realmente útil que ofrecer.

(Traducido del inglés)

\footnotetext{
${ }^{10}$ En una encuesta realizada en 1997 entre 300 empresas del sector privado en Santiago, se observó que un porcentaje sorprendente de los empleadores - $83.7 \%$ - consideraba que los sindicatos contribuían a las relaciones laborales, y que sólo $6 \%$ creía que las dificultaban más. Entre los líderes sindicales, $65.3 \%$ manifestó que los empleadores facilitaban casi siempre la labor de los sindicatos (citado en The Economist Intelligence Unit, 1998).
} 


\section{Bibliografía}

Amadeo, E.J. y J. M. Camargo (1997): Brazil: regulation and flexibility in the labor market, S. Edwards y N. Lustig (eds.), Labor Markets in Latin America, Washington, D.C., Brookings Institution.

Banco Mundial (1999): World Development Indicators 1999, CD-ROM. BID (Banco Interamericano de Desarrollo) (s/f): Economic and Social Data Base, http://database.iadb.org/esdbweb/scripts/ esdbweb.exe

Bordo, M.D., C. Goldin y E.N.White, eds. (1998): The Defining Moment: The Great Depression and the American Economy in the Twentieth Century, Chicago, Illinois, University of Chicago Press.

Cortázar, R. (1997): Chile: The evolution and reform of the labor market, en S. Edwards y N. Lustig (eds.), Labor Markets in Latin America, Washington, D.C., Brookings Institution.

Domínguez, J. (1997): Latin America's crisis of representation, Foreign Affairs, vol. 76, № 1, Nueva York, Council on Foreign Affairs, Inc.

(1998): Free politics and free markets in Latin America, Journal of Democracy, vol. 9, $\mathrm{N}^{\circ} 1$, Nueva York, Council of Foreign Relations, octubre.

Easterly, W., R. Islam y J. E. Stiglitz (1999): Shaken and Stirred: Volatility and Macroeconomic Paradigms for Rich and Poor Countries, Michael Bruno Memorial Lecture, XII World Congress of the IEA, Buenos Aires, Asociación Internacional de Evaluación del Rendimiento Escolar, 27 de agosto.

Ferreira, F.H. y R. Paes de Barros (1999): The Slippery Slope: Explaining the Increase in Extreme Poverty in Urban Brazil, 1976-1996, Texto para discussão, No 404, Rio de Janeiro, Pontificia Universidad Católica de Rio de Janeiro.

FMI (Fondo Monetario Internacional) (varios años): International Financial Statistics, Washington, D.C.

Gavin, M. (1999): Latin American central banks: Reticent to react, Latin American Economic Policies, vol. 7, Washington, D.C., BID, Office of the Chief Economist.

Gavin, M. y R. Hausmann (1996): Sources of Macroeconomic Volatility in Developing Economies, Washington, D.C., BID.

Glewwe, P. y G. Hall (1998): Are some groups more vulnerable to macroeconomic shocks than others? Hypothesis test based on panel data from Peru, Journal of Development Economics, vol. 56, $\mathrm{N}^{\circ} 1$, Amsterdam, Países Bajos, Elsevier Science Publishers, B,V.

Hausmann, R. y M. Gavin (1996): Securing Stability and Growth in a Shock Prone Region: The Policy Challenge for Latin America, Washington, D.C., BID.

Jacoby, S.M. (1998): Risk and the Labor Market: Societal Past as Economic Prologue, Los Angeles, California, Universidad de California, Institute of Industrial Relations.
Jaggers, K. y T.R. Gurr (1995): Tracking democracy's third wave with Polity III data, Journal of Peace Research, vol. 32, Oslo, International Peace Research Institute Oslo (PRIO).

Lustig, N. (ed.) (1995): Coping with Austerity: Poverty and Inequality in Latin America, Washington, D.C., Brookings Institution.

Lustig, N. (1999): Crises and the Poor: Socially Responsible Macroeconomics, Washington, D.C., BID, septiembre.

Márquez, G. y C. Pages (1998): Ties That Bind: Employment Protection and Labor Market Outcomes in Latin America, Washington, D.C., BID, febrero.

Mirror on the Americas Poll (1999): Nueva York, Wall Street Journal Interactive Edition.

OIT (Organización Internacional del Trabajo) (1997): World Labour Report 1997-1998, Ginebra.

(1998): Studies in the Social Dimensions of Globalization, Ginebra.

(1999): Progress Report on the Country Studies on the Social Impact of Globalization, Ginebra, 24 de marzo.

Pencavel, J. (1997): The legal framework for collective bargaining in developing economies, en S. Edwards y N. Lustig (eds.), Labor Markets in Latin America, Washington, D.C., Brookings Institution.

Pessino, C. (1997): Argentina: The labor market during the economic transition, en S. Edwards y N. Lustig (eds.), Labor Markets in Latin America, Washington, D.C., Brookings Institution.

Rockoff, H. (1998): By way of analogy: The expansion of the federal government in the 1930s, en M.D. Bordo y otros (eds.), The Defining Moment: The Great Depression and the American Economy in the Twentieth Century, Chicago, Illinois, University of Chicago Press.

Rodrik, D. (1997): Has Globalization Gone Too Far?, Washington, D.C., Institute for International Economics (IIE). (1998): Where has all the growth gone? External shocks, social conflict, and growth collapses, Journal of Economic Growth, № 4, Boston, Kluwer Academic Publishers.

(1999): The New Global Economy and Developing Countries: Making Openness Work, Washington, D.C., Consejo de Desarrollo de Ultramar.

Romero, S. (1999): Brazilians eagerly seek a big bank's entry level jobs, The New York Times, Nueva York, 26 de agosto.

The Economist Intelligence Unit (1998): Country Report for Chi$l e$, Londres, 17 de agosto.

Taylor-Gooby, P. (1989): The role of the state, en R. Jowell y otros, British Social Attitudes: Special International Report, vol. 6, Aldershot, Reino Unido, Gower Publishing. 